\title{
How Informative Are Central Bank Assessments of Macroeconomic Risks?*
}

\author{
Malte Knüppel and Guido Schultefrankenfeld \\ Deutsche Bundesbank
}

\begin{abstract}
Many central banks publish regular assessments of the magnitude and balance of risks to the macroeconomic outlook. In this paper, we analyze the statistical properties of the inflation risk assessments that have been published by the Bank of England and the Sveriges Riksbank. In each case, we find no significant evidence of any systematic connection between the ex ante risk assessments and the ex post forecast errors at horizons from zero to eight quarters. These results illustrate the difficult challenges in making accurate real-time assessments of temporal changes to the distribution of forecast errors.
\end{abstract}

JEL Codes: E37, C12, C53.

\section{Introduction}

If Banks routinely report risk assessments, then those assessments should be systematically evaluated, just as the accuracy of Banks' inflation forecasts are evaluated. . . . If such an analysis finds no systematic connection between risk assessments and

\footnotetext{
${ }^{*}$ A previous version of this paper was entitled "How Informative Are Macroeconomic Risk Forecasts? An Examination of the Bank of England's Inflation Forecasts" and published as Deutsche Bundesbank Discussion Paper No. 14/2008. The authors would like to thank an anonymous referee, Jörg Breitung, Heinz Herrmann, Martin Summer, Karl-Heinz Tödter, and seminar participants at the Bank of England, the Deutsche Bundesbank, and the Swiss National Bank for very helpful comments and discussions. Particular thanks go to the Associate Editor, Andrew Levin, for providing many suggestions that helped to improve this study. This paper represents the authors' personal opinions and does not necessarily reflect the views of the Deutsche Bundesbank. Corresponding author (Knüppel): malte.knueppel@bundesbank.de. Postal address: Deusche Bundesbank, Wilhelm-Epstein-Str. 14, D-60431 Frankfurt am Main, Germany.
} 
forecast errors, then the value of the risk assessments is called into question.

$$
\text { —Eric Leeper (2003, p. 16) }{ }^{1}
$$

Today, most major central banks publish point forecasts for macroeconomic variables that play an important role in the monetary policy decision-making process. Moreover, many central banks also provide an assessment of the uncertainty surrounding these forecasts. In addition to this information, a large share of central banks issues statements about the probability of future outturns lying above or below the point forecasts, i.e., about the asymmetry of the forecast density. In these statements, the term "risk" generally appears. A single risk to the forecast is usually understood to be a possible future event whose occurrence would lead to outturns that differ markedly from the point forecasts. Statements about "the overall risks," "the balance of risks," or simply "the risks" to a certain variable then apparently often refer to the entire set of single risks that have been identified and weighted by their perceived probabilities of materialization as well as their potential impact. These statements are supposed to contain information about the asymmetry of the forecast density. For example, a typical statement of this kind can read as follows: "Most participants viewed the risks to their projections for GDP growth as weighted to the downside." 2 We will further elaborate on central banks' use of the term "risk" below.

Determining the asymmetry of a forecast density, i.e., forecasting a phenomenon related to third moments, is certainly an extremely challenging task. This might be illustrated by the fact that many central banks simply base their assessment of forecast uncertainty, i.e., a phenomenon related to second moments and therefore generally easier to assess, on past forecast errors. ${ }^{3}$ This is due to the lack of models which can accomplish this task, as explained by Wallis (1989). However, if it is so difficult to forecast the uncertainty surrounding

\footnotetext{
${ }^{1}$ In a footnote, Eric Leeper thanks Stefan Palmqvist for making this suggestion.

${ }^{2}$ See Board of Governors of the Federal Reserve System (2008, p. 41). Henceforth, we will refer to the Board of Governors of the Federal Reserve System simply as the Federal Reserve.

${ }^{3}$ See Deutsche Bundesbank (2010, pp. 34-36) for an overview.
} 
an institution's forecast appropriately, it is questionable whether risks can be forecast in a reasonable manner. Given that so many institutions engage in risk forecasting despite the difficulties encountered, it is important and interesting to find out how successful these risk forecasts are.

In this paper, we concentrate on risk forecasts for inflation published by the Bank of England (henceforth BoE) and the Sveriges Riksbank (henceforth Riksbank) due to data availability. To the best of our knowledge, there have hardly been any investigations of risk forecasts in the literature. For the BoE, which has the longest riskforecasting record, risk forecasts have at best been evaluated in the context of investigations of the entire forecast density. For instance, Wallis (2003, p. 165) states that "the excessive concern with upside risk was not justified over the period considered." In a comprehensive study of the BoE's density forecasts, Mitchell and Hall (2005) note that the null hypothesis of equal density forecast accuracy for the BoE's asymmetric and the corresponding symmetric forecast densities could not be rejected. Both studies focus on one-year-ahead inflation forecasts. ${ }^{4}$

While these results already hint at the existence of problems with the risk forecasts, it still remains to be analyzed whether there is a systematic connection between the BoE's risk forecasts and its forecast errors. If there is a systematic connection, and if the point forecast is a mode forecast, then upside (downside) risks should on average be followed by outturns that are greater (less) than the point forecasts. Moreover, the magnitude of the mode forecast error should on average correspond to the magnitude of the (suitably defined) forecast risk. If this is the case, the risk forecasts can be considered optimal. ${ }^{5}$ If there is no systematic connection, i.e., if the risk forecasts do not help to predict the mode forecast errors, the risk forecasts are uninformative.

The analysis in this study is performed in the context of tests for forecast optimality similar to those of Mincer and Zarnowitz (1969).

\footnotetext{
${ }^{4}$ Wallis (2003) does not find major problems when studying the inflation nowcasts.

${ }^{5}$ To be more precise, they would at least be considered partially optimal in the sense of Diebold and Lopez (1996). The concept of optimality used in this paper will become clear in section 4 .
} 
It turns out that there is considerable evidence against the optimality of risk forecasts, at least for the BoE. For both central banks under study, we fail to find robust evidence that risk forecasts have the intended information content. Put differently, it seems that there is no systematic connection between risk forecasts and mode forecast errors.

The outline of the paper is as follows. We present a survey of current risk-forecasting practices at several central banks in section 2 . In section 3, we give an overview of our forecast data set. In section 4, we explain the methodology used, and section 5 follows with a detailed analysis of the risk forecasts of the BoE and the Riksbank with respect to optimality and informativeness. In section 6 , we briefly address reasons for risk forecasting in light of the apparent lack of information content found in section 5 . Section 7 concludes.

\section{An Overview of Risk Forecasting}

Although the term "risk" is used in many forecasting-related central bank publications, there is no unique definition of its meaning. In the New Palgrave Dictionary of Economics, Machina and Rothschild (2008) state that "a situation is said to involve 'risk' if the randomness facing an economic agent presents itself in the form of exogenously specified or scientifically calculable objective probabilities, as with gambles based on a roulette wheel or a pair of dice." However, the term "risk" as used by central banks often refers to important events with a rather uncertain probability of occurrence, like a large change in oil prices or in exchange rates. A different interpretation of the term "risk" is provided by Kilian and Manganelli (2007), who link the risks to the preferences of central bankers. This might be a valid interpretation with respect to several statements made by the Federal Reserve during a certain period. It is not adequate, though, for the current risk forecasts of the Federal Reserve and many other central banks, among others those whose data are investigated in this study.

Many central banks devote a kind of stand-alone publication such as a box, a chapter, or an article to their respective definitions of risk. An example-based yet precise definition is given by the BoE in Britton, 
Fisher, and Whitley (1998, pp. 32-33). ${ }^{6}$ According to the BoE, a risk is given by an uncertain and important event not taken into account in the central view, where the central view - i.e., the point forecastcorresponds to the mode of the forecast density. In contrast to the definition of Machina and Rothschild (2008), the probability of the event is not exogenously specified or scientifically calculable, and in contrast to the interpretation of Kilian and Manganelli (2007), the risk is unrelated to the preferences of the central bank. The balance of risks refers to the probabilities of the events mentioned producing values above or below the point forecast. The balance of risks is thus directly related to the skewness of the forecast density, which, in the case of the BoE, is measured as the difference between the mean and the mode of the forecast density. In figure 1, two asymmetric forecast densities from the BoE are displayed.

The fact that the mode (and not the mean) of the forecast density serves as the BoE's point forecast appears surprising, since aiming at the mode is associated with a rather implausible all-or-nothing loss function of the policymaker. ${ }^{7}$ Interestingly, however, nearly all of the central banks we consider in this study as listed in table 1 specifically indicate that their point forecasts are mode forecasts. ${ }^{8}$

\footnotetext{
${ }^{6}$ It reads as follows:

In deciding upon central assumptions and risks across key components of the forecast, it may become clear that the risks are unbalanced. A good example of this is the effect of "windfall" gains to consumers from the conversion of several building societies to banks in 1997. Uncertainty about the pace at which the windfalls would be spent represented a risk to the forecast of consumer spending. The Bank's theoretical analysis suggested that only a small proportion of these gains would be spent in the first year, and correspondingly took this as a central view. In the Bank's judgment, the risks were much greater that actual expenditure would be in excess of the central forecast assumption than that it would be less. This was an upside risk to the forecast during most of 1997. In order to produce the fan chart, only one number is needed to summarise the degree of skewness (the balance of risks). Just as with the central view and the degree of uncertainty, there is more than one possible choice of parameter. The Bank's analysis focuses on the difference between the mean and the mode of the forecast distribution to be presented in the Report. This difference is of interest as a summary statistic of the balance of risks.
}

${ }^{7}$ See Wallis (1999) for a discussion.

${ }^{8}$ From table 1, only the Bank of Israel and the Swiss National Bank do not explicitly characterize the meaning of their point forecasts. Moreover, the Bank of Japan and the Federal Reserve do not produce unified forecasts but instead publish summary statistics and histograms of modal forecasts from individual policymakers. The European Central Bank only publishes forecast ranges. 


\section{Figure 1. Two of the Bank of England's Density Forecasts for Inflation}
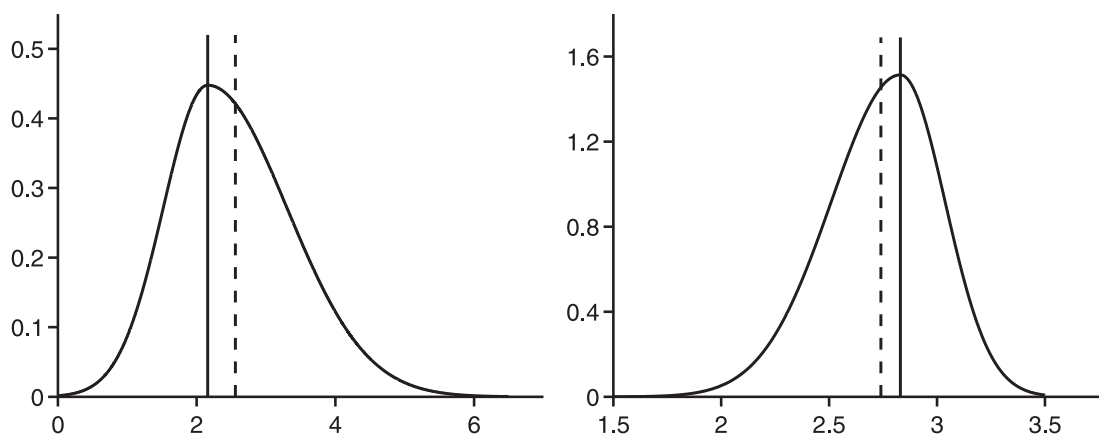

Notes: The forecast in the left-hand panel, made in the second quarter of 2002 for the first quarter of 2004, implies an upward risk, where the mean (dashed vertical line) exceeds the mode (solid vertical line). The forecast in the righthand panel, made in the second quarter of 1998 for the same quarter, implies a downward risk, with the mean (dashed vertical line) falling short of the mode (solid vertical line).

Definitions of risk similar to the one used by the BoE can be found in the publications of other central banks. The Riksbank (1998, p. 36) writes:

Two aspects of the forecast distribution are assessed subjectively: whether the uncertainty in the forecast differs from the historical uncertainty ...., and whether the risk of forecasting errors is symmetric, upside or downside. In the absence of information to the contrary, the risk is assumed to be symmetric. . . . A skewed uncertainty (a difference between the upside and downside risks in the assessment of a particular variable, e.g. imports) affects the distribution of the inflation forecast by the amount of the variable's weight in the macro model. Skew is measured as the difference between the mean value and the most probable value (the mode of the distribution).

Again, the mode forecast serves as the point forecast. Further details concerning the forecasts of the Riksbank can be found in Blix and Sellin (1999). However, the Riksbank changed its forecasting procedure in 2007. Since then, it has only published symmetric forecast densities and has not mentioned the balance of risks, 
Table 1. Central Bank Assessments of Macroeconomic Balances of Risks

\begin{tabular}{|c|c|c|c|c|}
\hline $\begin{array}{l}\text { Central } \\
\text { Bank }\end{array}$ & $\begin{array}{c}\text { Type } \\
\text { of } \\
\text { Assessment }\end{array}$ & $\begin{array}{c}\text { Assessment } \\
\text { of Inflation } \\
\text { Risk }\end{array}$ & $\begin{array}{c}\text { Assessment } \\
\text { of } \\
\text { Real Risk }\end{array}$ & $\begin{array}{c}\text { Publication } \\
\text { of } \\
\text { Fan Charts }\end{array}$ \\
\hline $\begin{array}{l}\text { Bank of } \\
\text { Canada }\end{array}$ & Quantitative & Yes & No & Asymmetric \\
\hline $\begin{array}{l}\text { Banco Central } \\
\text { de Chile }\end{array}$ & Quantitative & Yes & Yes & Asymmetric \\
\hline $\begin{array}{l}\text { Bank of } \\
\text { England }\end{array}$ & Quantitative & Yes & Yes & Asymmetric \\
\hline $\begin{array}{l}\text { Banco de } \\
\text { España }\end{array}$ & Qualitative & Yes & Yes & Symmetric \\
\hline Bank of Israel & Qualitative & Yes & No & Symmetric \\
\hline Bank of Japan & Quantitative & Yes & Yes & None \\
\hline $\begin{array}{l}\text { Banco de } \\
\text { Portugal }\end{array}$ & Quantitative & Yes & Yes & Asymmetric \\
\hline $\begin{array}{l}\text { Board of } \\
\text { Governors } \\
\text { of the } \\
\text { Federal } \\
\text { Reserve } \\
\text { System }\end{array}$ & Qualitative & Yes & Yes & None \\
\hline $\begin{array}{l}\text { Deutsche } \\
\text { Bundesbank }\end{array}$ & Qualitative & Yes & Yes & Symmetric \\
\hline $\begin{array}{l}\text { European } \\
\quad \text { Central Bank }\end{array}$ & Qualitative & Yes & Yes & None \\
\hline $\begin{array}{l}\text { International } \\
\text { Monetary } \\
\text { Fund }\end{array}$ & Quantitative & Yes & Yes & Asymmetric \\
\hline $\begin{array}{l}\text { Magyar } \\
\text { Nemzeti } \\
\text { Bank }\end{array}$ & Quantitative & Yes & Yes & Asymmetric \\
\hline Norges Bank & None & No & No & Symmetric \\
\hline $\begin{array}{l}\text { Reserve Bank } \\
\text { of Australia }\end{array}$ & Qualitative & Yes & Yes & None \\
\hline $\begin{array}{l}\text { Reserve Bank } \\
\text { of New } \\
\text { Zealand }\end{array}$ & Qualitative & Yes & Yes & None \\
\hline
\end{tabular}




\section{Table 1. (Continued)}

\begin{tabular}{|l|l|c|c|l|}
\hline $\begin{array}{l}\text { Central } \\
\text { Bank }\end{array}$ & $\begin{array}{c}\text { Type } \\
\text { of } \\
\text { Assessment }\end{array}$ & $\begin{array}{c}\text { Assessment } \\
\text { of Inflation } \\
\text { Risk }\end{array}$ & $\begin{array}{c}\text { Assessment } \\
\text { of } \\
\text { Real Risk }\end{array}$ & $\begin{array}{c}\text { Publication } \\
\text { of } \\
\text { Fan Charts }\end{array}$ \\
\hline $\begin{array}{c}\text { Sveriges } \\
\text { Riksbank } \\
(2007-\end{array}$ & None & No & No & Symmetric \\
$\begin{array}{c}\text { Present) } \\
\text { Sveriges } \\
\text { Riksbank } \\
(1999-2006)\end{array}$ & Quantitative & Yes & No & Asymmetric \\
$\begin{array}{c}\text { Swiss } \\
\text { National } \\
\text { Bank }\end{array}$ & Qualitative & Yes & Yes & None \\
\hline
\end{tabular}

but just scenarios and risks. The Riksbank (2009, p. 22) now states that "the forecasts in the main scenario show the path which the Riksbank expects the economy to take and is a weighted consideration of various conceivable development paths (scenarios) and risks." Therefore, its main forecast currently seems to be a mean forecast. The Norges Bank appears to use the same approach.

Other central banks have followed the path set out by the BoE and the Riksbank. For example, the Magyar Nemzeti Bank (2004, p. 108) writes that "the method that we follow in preparing fan charts broadly corresponds to that of the Bank of England, and the same holds true for the Swedish method."

The Federal Reserve (2008, p. 45) explains that the members of the Board of Governors and the presidents of the Federal Reserve Banks "provide judgements as to whether the risks to their projections are weighted to the upside, downside, or are broadly balanced. That is, participants judge whether each variable is more likely to be above or below their projections of the most likely outcome." Hence, in contrast to the approaches mentioned so far, the risk assessments are only qualitative (naming upside, downside, or broadly balanced risks) and not quantitative. This means that there is no number attached to the risk forecasts; only the direction of the risk is given. The same applies to the risk forecasts of the European Central Bank (henceforth ECB). For example, the ECB (2010, p. 6) states that 
"in the Governing Council's assessment, the risks to this improved economic outlook are slightly tilted to the downside." 9

Several other central banks also link the overall forecast risks to the asymmetry of the forecast density, among them the Bank of Canada, the Banco Central de Chile, the Banco de España, the Bank of Japan, the Banco de Portugal, the Deutsche Bundesbank, and the International Monetary Fund (henceforth IMF). ${ }^{10}$ Details concerning the corresponding references are provided below.

We also found central banks which regularly report their assessments of individual risks but which do not always mention the balance of these risks. For example, the Reserve Bank of Australia (2008, p. 68) states that "risks to these forecasts can be identified in both directions. A further deterioration in the outlook for global growth would be the main source of downside risk to the forecasts for domestic activity." Another example is the Swiss National Bank (2010b, p. 40), which declares that "the biggest risk for the global economy is the continued increase in tension on financial markets. ... At the same time, there are upside risks for the global economy." In both cases, no overall assessment of risks follows. Yet sometimes such an assessment is made by these central banks. ${ }^{11}$ The Reserve Bank of New Zealand behaves similarly to the two aforementioned central banks, making clear statements concerning the overall risks on some occasions and mentioning only individual risks on others. The same applies to the Bank of Israel.

In table 1 , we present an overview of the risk-forecasting practices of several central banks. Of course, this table only reflects the current

\footnotetext{
${ }^{9}$ However, the ECB often also mentions "risks to price stability," where the term "risks" instead appears to refer to the possibility that the ECB might not achieve its "aim of keeping inflation rates below, but close to, $2 \%$ over the medium term" (ECB 2010, p. 6). In this case, the risks are apparently unrelated to the asymmetry of a forecast density. Note that the risks to price stability can also be asymmetric, as described in the statements: "The information that has become available ... has confirmed that ... upside risks to price stability over the medium term prevail" (ECB 2008, p. 5). Yet this asymmetry supposedly just refers to the probability of observing inflation rates above 2 percent over the medium term being larger than 50 percent, and is therefore also unrelated to the asymmetry of forecast densities.

${ }^{10}$ The IMF is an intergovernmental organization, but we consider it here because its interpretation of risk forecasts is identical to that used by most central banks.

${ }^{11}$ For example, the Swiss National Bank (2010a, p. 26) claims that "at present, the upside and downside risks are relatively balanced" for output growth.
} 
situation, and the approaches to risk forecasting might change over time, as in the case of the Riksbank. Moreover, in some cases we have not been able to discover statements concerning the balance of risks, but it is not impossible that these exist. ${ }^{12}$ All central banks shown in the table regularly discuss risks to their forecasts. ${ }^{13}$ Furthermore, as mentioned above, almost all of these central banks use the mode forecast as their central forecast.

All central banks shown in the table which make precise statements concerning the meaning of the balance of risks use at least one of the following definitions. If the balance of risks for a certain variable is tilted to the upside, this means that the expected value of that variable exceeds the most likely value (i.e., the point forecast which is identical to the mode forecast), that the probability of an outturn above the point forecast is more likely than an outturn below, or that the forecast density is positively skewed. ${ }^{14}$ Thus balanceof-risks statements are supposed to contain information about the potential asymmetry of the forecast density.

It should be noted that, for many asymmetric distributions, the above-mentioned inequalities $E[Y]>\operatorname{mode}(Y), P(y>\operatorname{mode}(Y))>$ $P(y<\operatorname{mode}(Y))$, and $E\left[(Y-E[Y])^{3}\right]>0$ imply each other. ${ }^{15}$ This holds, for example, in the case of the two-piece normal distribution used by the BoE, the Magyar Nemzeti Bank, the IMF, and the Riksbank (until 2006) for their asymmetric fan charts. ${ }^{16}$ Therefore, potential differences in the technical definitions of the balance of risks are probably irrelevant in actual practice.

It is perfectly possible for a central bank to consider the balance of risks to be asymmetric and nevertheless publish symmetric fan charts, as in the case of the Deutsche Bundesbank, the Banco de España, or the Bank of Israel. This could be due to the fact that these central banks, like many others, assess the balance of risks in

\footnotetext{
${ }^{12}$ We corresponded with members of several central banks in order to minimize the possibility of certain definitions having slipped our attention.

${ }^{13}$ Table 6 in appendix 1 lists where these discussions can be found.

${ }^{14}$ In appendix 1, we provide the references on which several of the statements made above and table 1 are based.

${ }^{15}$ The same applies to the reversed inequalities $E[Y]<\operatorname{mode}(Y), P(y>$ $\operatorname{mode}(Y))<P(y<\operatorname{mode}(Y))$, and $E\left[(Y-E[Y])^{3}\right]<0 . E[Y]$ denotes the expectation of $Y$ and $P(A)$ the probability of event $A$.

${ }^{16}$ We will elaborate on this distribution below.
} 
a qualitative manner only. Asymmetric fan charts tend to be used if quantitative risk assessments are produced. The Banco de Portugal and the Riksbank (1999-2006) are the only central banks which also release figures measuring the risk of the forecast density in their main publications. ${ }^{17}$ The Banco de Portugal shows the probabilities of an outturn below the central projection. The Riksbank (19992006) publishes the values of the mode and the mean of the forecast density.

Reading through central bank publications, it seems that risks to inflation or other aggregates are commonly identified via risks to variables that determine these aggregates. For example, an upward risk to inflation might be caused by an upward risk to oil prices, to the value-added tax (henceforth VAT) rate, or by a risk of the domestic currency depreciating. Thus, in order to correctly forecast the risks to inflation, one has to forecast the risks to these determinants. Actually, the process of risk forecasting could be thought of as a three-step process. In the first step, those determinants which are subject to forecast risks have to be identified. In the second step, these risks must be quantified, and in the third step, their impact on the aggregate of interest has to be calculated.

All of these steps appear extremely demanding. The first step requires the identification of variables whose most likely future paths (represented by the mode forecast) differ from their expected future paths (represented by the mean forecast). This might be possible for fiscal variables like the VAT rate, where one could imagine that a certain rate is likely but that an alternative rate is being discussed by the government at the time the forecast is made. For variables like oil prices and exchange rates, however, this task is very challenging. The subsequent quantification of the identified risks appears fairly difficult as well. Elekdag and Kannan (2009) propose methods for accomplishing this task which can be applied to certain variables. However, their empirical performance is not evaluated. Apparently, most central banks rely on judgment for identifying as well as quantifying risks. Yet even if the risks to determinants are correctly identified and quantified, assessing their impact on the aggregate of interest is no trivial matter, as explained in Pinheiro and Esteves (2010).

\footnotetext{
${ }^{17}$ Figures for the BoE's and the Magyar Nemzeti Bank's density forecasts can be downloaded from the respective web sites.
} 
To summarize, all central banks considered discuss risks to their forecasts, and many of them also assess the balance of these risks. The balance of risks is supposed to contain information about the asymmetry of the forecast density. The published point forecast corresponds to the mode of the forecast density for almost all central banks. In the following, the term "risk forecast" will refer to the balance-of-risks forecast, i.e., to a potentially asymmetric forecast density. It will thus not denote the assessment of certain individual risks without the evaluation of their overall effect on the forecast variable of interest.

\section{Data}

\subsection{Data Sources}

The risk-forecasting record of most central banks is very limited. As explained in Knüppel and Schultefrankenfeld (2011), inference concerning risk forecasts tends to be easier with quantitative than with qualitative risk forecasts. Therefore, we focus on data sources where quantitative risk forecasts are available. The first quantitative risk forecast that we are aware of was published by the BoE in its Inflation Report from February 1996 for inflation. ${ }^{18}$ As mentioned before, the Riksbank issued quantitative risk assessments from 1999 to 2006. Our subsequent analysis will be restricted to the risk forecasts of these two central banks, because the quantitative risk forecasts of the other institutions shown in table 1 are (still) unsuitable for evaluation purposes. ${ }^{19}$

\footnotetext{
${ }^{18}$ According to the numerical parameters that can be downloaded at www.bankofengland.co.uk/publications/inflationreport/irprobab.htm, the skewness of the forecast density then differed from zero for the first time.

${ }^{19}$ The Banco de Portugal started to publish quantitative risk forecasts in December 2003, but these are annual forecasts, which means that only very few observations are available. The IMF and the Bank of Japan only release annual risk forecasts, too. The Bank of Canada and the Banco de Chile do not publish data which allow a calculation of their quantitative forecast risks. Finally, the quantitative risk-forecasting record of the Magyar Nemzeti Bank dates back to its Inflation Report from November 2002, and its forecasts have a quarterly frequency. However, the magnitudes of the asymmetries we backed out from its density forecast data are far too small for reliable inference about risk-forecast optimality and informativeness. The asymmetries were backed out in a similar way as described for the Riksbank in appendix 2. Further details are available upon request.
} 
The BoE and the Riksbank use the two-piece normal distribution (henceforth tpn-distribution) as described, for example, in Wallis (2004, p. 66). Our analysis utilizes the BoE's forecasts for inflation, based on the assumption that the future official Bank Rate, i.e., the interest rate paid on commercial bank reserves, follows a path implied by market interest rates. ${ }^{20}$ In line with Elder et al. (2005), for the purpose of forecast evaluations we consider this assumption more adequate than that of a constant official Bank Rate. The forecast and inflation data range from the first quarter of 1998 (henceforth 1998:Q1) — the first time the aforementioned interest assumption was used - to 2010:Q2. Each of the BoE's quarterly projections covers the current and the subsequent eight quarters. For some forecasts, mean and mode forecast coincide, which results in a risk forecast equal to zero. This means that the risks to the inflation forecast are balanced. ${ }^{21}$ The BoE publishes several parameters of the forecast densities that allow a straightforward calculation of the Pearson mode skewness which will serve as our risk measure. The Pearson mode skewness of a density is defined as the mean-mode difference divided by the standard deviation.

Our forecast data set from the Riksbank starts in December 1999, when the data used to produce the fan charts of the respective Inflation Report were made publicly available on the Riksbank's web site for the first time. ${ }^{22}$ The last asymmetric fan chart appeared in October 2006. From 1999 to 2005, there were always four Inflation Reports per year, namely in February/March/April, May/June, October, and December. Like the Riksbank, we will refer to these as the Inflation Reports $\mathrm{y}: 1, \mathrm{y}: 2, \mathrm{y}: 3$, and $\mathrm{y}: 4$, respectively, where "y" stands for the year. There was no Inflation Report 2006:4, and since 2007, the fan charts of the Monetary Policy Reports, which succeeded the Inflation Reports, have always been symmetric.

\footnotetext{
${ }^{20}$ Until 2003, the BoE used to forecast the inflation of the All Items Retail Price Index excluding mortgage interest payments (RPIX). Since 2004, it has forecast CPI inflation.

${ }^{21}$ The BoE also publishes risk forecasts for GDP. We do not study these forecasts here, since the analysis of GDP risk forecasts would be more complicated due to the effects of data revisions. Such revisions play a substantial role for the assessment of the BoE's GDP forecasts, as noted by Elder et al. (2005).

${ }^{22}$ See www.riksbank.se/templates/DocumentList.aspx?id $=5031$.
} 
Therefore, our data sample covers the forecasts from the Inflation Reports from 1999:4 to 2006:3. ${ }^{23}$

A potential drawback of the data from the Riksbank is given by the constant interest rate assumption underlying the forecasts in the Inflation Reports 1999:4 to 2005:2; i.e., it was assumed that the interest rates do not change during the forecasting period but remain on the level they had attained at the time the forecast was produced. Starting with the Inflation Report 2005:3, the forecasts have been conditioned on interest rates expected by market participants. ${ }^{24}$

In the case of a constant interest rate assumption, it might be difficult to assess the optimality of risk forecasts, at least for larger horizons. For example, if the constant interest rate assumption leads to inflation forecasts that exceed the target at the relevant policy horizon, the policymaker is likely to raise the policy rate to dampen inflation. Thus, the inflation forecast error mainly depends on the point forecast for inflation, and only to a very limited extent on the risk forecast. ${ }^{25}$ For short horizons, however, testing for risk-forecast optimality should be possible even with a constant interest rate assumption for two reasons. Firstly, a constant interest rate assumption is probably a good approximation to the behavior of interest rates in the short run. Secondly, inflation responds to changes in the interest rate only with a certain delay. Therefore, in case of the Riksbank, we will only consider risk forecasts for up to four quarters ahead.

The Riksbank forecasts two monthly inflation measures, where we decide to focus on CPI inflation only. From the available twenty-four forecast horizons, we use every third monthly forecast for up to four quarters ahead. We are therefore left with five forecast horizons, always with one observation per quarter. ${ }^{26}$ The shortest forecast horizon is chosen such that it contains a forecast for the

${ }^{23}$ Unfortunately, the forecast data from the Inflation Report 2000:1 are not available, which means that our sample contains only twenty-seven instead of twenty-eight forecasts.

${ }^{24}$ See Sveriges Riksbank (2005, p. 57).

${ }^{25}$ Only if the central inflation forecast implies that inflation will be close to target could the inflation forecast error be well predicted by the risk forecast if the risk forecast is optimal.

${ }^{26}$ Using all monthly forecasts yields practically no additional insights, since the monthly risk forecasts are quantitatively very similar for adjacent forecast horizons, and the forecast errors of adjacent horizons are often similar, too. Moreover, the results can be compared more easily with those for the BoE using every third monthly forecast only. 
month of the publication of the Inflation Report, meaning that this forecast is actually a nowcast. Thus, we consider the Riksbank's zero-, three-, six-, nine-, and twelve-month-ahead forecasts. In contrast to the BoE, the Riksbank only published the mode of the forecast density and the values of several quantiles. From these data and the corresponding statements in the Inflation Reports, we carefully back out the parameters which permit calculation of the Pearson mode skewness of the forecast densities. Details are provided in appendix 2 .

The risk forecasts of the BoE and the Riksbank as measured by the Pearson mode skewness of the forecast densities are displayed in tables 7 and 8 in appendix 2 for all forecast horizons. For ease of exposition, in the following we focus on the results for even horizons, i.e., BoE results for $h=0,2,4,6,8$ and Riksbank results for $h=0,2,4 .^{27}$ No major insights are lost by leaving the odd horizons aside.

\subsection{Summary Statistics}

Before turning to the empirical tests, it is useful to take a brief look at the forecast risks and the associated realized risks used in this study. The forecast risk, measured by the Pearson mode skewness, is defined as $\left(\hat{\mu}_{t+h \mid t}-\hat{m}_{t+h \mid t}\right) / \hat{\sigma}_{t+h \mid t}$, where $\hat{\mu}_{t+h \mid t}$ is the mean forecast for period $t+h$ made in period $t, \hat{m}_{t+h \mid t}$ is the corresponding mode forecast, and $\hat{\sigma}_{t+h \mid t}$ is the corresponding forecast of the standard deviation. ${ }^{28}$ Our measure of realized risk is given by the scaled mode forecast error, i.e., by $\left(y_{t+h}-\hat{m}_{t+h \mid t}\right) / \hat{\sigma}_{t+h \mid t}$, where $y_{t+h}$ is the realization of the forecast variable in period $t+h$. Figure 2 shows horizon-specific scatter plots of forecast and realized risks for the BoE and the Riksbank. The lower right-hand panel contains all data from the previous plots summarized in a single scatter plot. The largest forecast risks equal about 0.5 , the smallest about -0.3 . The realized risks, i.e., the scaled mode forecast errors, range from about -2.6 to about 4.5 . For a large number of periods, the risks were actually forecast to be balanced.

\footnotetext{
${ }^{27}$ These quarterly horizons correspond to the the Riksbank's zero-, six-, and twelve-month-ahead forecasts, respectively.

${ }^{28}$ Further explanations concerning the use of the Pearson mode skewness follow in section 4 and computational details are provided in appendix 2 .
} 


\section{Figure 2. Scatter Plots for the Bank of England and the Sveriges Riksbank}

BoE, $h=0$

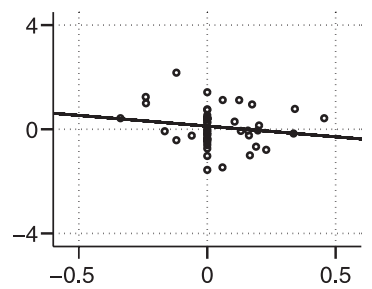

BoE, $h=6$

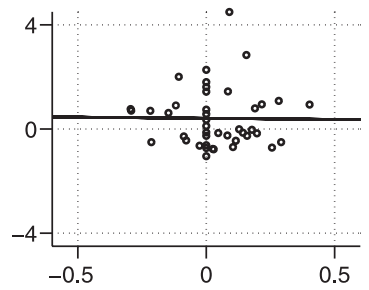

Riksbank, $h=2$

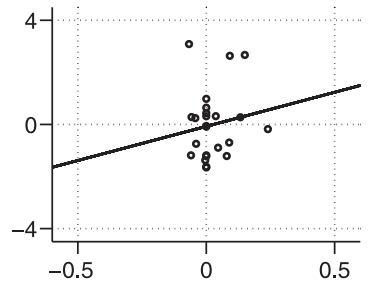

BoE, $h=2$

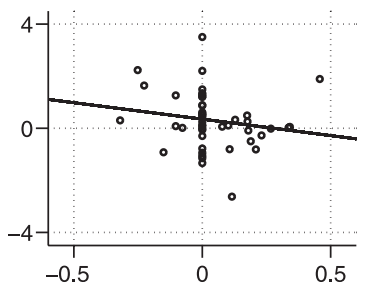

BoE, $h=8$

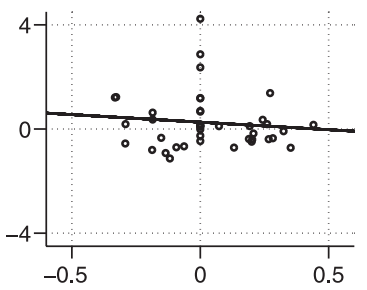

Riksbank, $h=4$

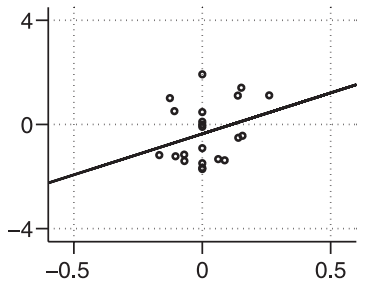

BoE, $h=4$

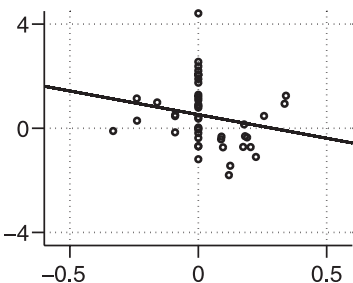

Riksbank, $h=0$

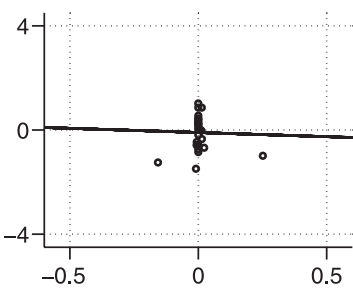

All

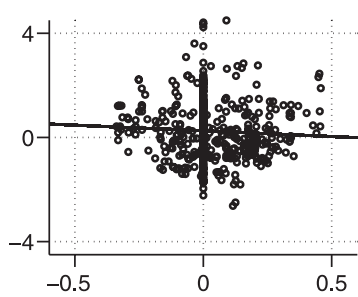

Notes: The forecast Pearson mode skewness is shown on the $\mathrm{x}$-axis, the scaled forecast error of the mode on the $\mathrm{y}$-axis. The lower right-hand panel is a scatter plot of all data of the Bank of England for $h=0,2,4,6,8$ and of the Sveriges Riksbank for $h=0,2,4$.

If the risk forecasts are optimal, most points in the scatter plots should be located in the first and third quadrant. If the risk forecasts are not informative, the points should spread broadly evenly above and below the zero line. ${ }^{29}$ Thus, the regression lines in all BoE data

\footnotetext{
${ }^{29}$ Of course, if the risk forecasts are not unbiased, the points would simply be shifted away from the zero line.
} 


\section{Table 2. Summary Statistics for Forecast Data of the Bank of England and the Sveriges Riksbank}

\begin{tabular}{|c|c|c|c|c|c|}
\hline $\boldsymbol{h}$ & 0 & 2 & 4 & 6 & 8 \\
\hline \multicolumn{6}{|c|}{ Bank of England } \\
\hline \multirow{5}{*}{$\begin{array}{l}\hat{m}_{t+h \mid t} \\
\hat{\mu}_{t+h \mid t}-\hat{m}_{t+h \mid t} \\
\hat{\sigma}_{t+h \mid t}^{2}\end{array}$} & \multicolumn{5}{|c|}{ Sample Average } \\
\hline & 2.35 & 2.23 & 2.06 & 2.03 & 2.14 \\
\hline & 0.01 & 0.03 & 0.03 & 0.04 & 0.04 \\
\hline & 0.08 & 0.29 & 0.43 & 0.58 & 0.77 \\
\hline & \multicolumn{5}{|c|}{ Interquartile Range } \\
\hline \multirow{3}{*}{$\begin{array}{l}\hat{m}_{t+h \mid t} \\
\hat{\mu}_{t+h \mid t}-\hat{m}_{t+h \mid t} \\
\hat{\sigma}_{t+h \mid t}^{2}\end{array}$} & 0.71 & 0.48 & 0.58 & 0.52 & 0.47 \\
\hline & 0.03 & 0.07 & 0.09 & 0.11 & 0.20 \\
\hline & 0.05 & 0.14 & 0.16 & 0.24 & 0.42 \\
\hline \multicolumn{6}{|c|}{ Sveriges Riksbank } \\
\hline \multirow{5}{*}{$\begin{array}{l}\hat{m}_{t+h \mid t} \\
\hat{\mu}_{t+h \mid t}-\hat{m}_{t+h \mid t} \\
\hat{\sigma}_{t+h \mid t}^{2}\end{array}$} & \multicolumn{5}{|c|}{ Sample Average } \\
\hline & 1.44 & 1.46 & 1.71 & & \\
\hline & 0.00 & 0.01 & 0.02 & & \\
\hline & 0.09 & 0.24 & 0.54 & & \\
\hline & \multicolumn{5}{|c|}{ Interquartile Range } \\
\hline \multirow{3}{*}{$\begin{array}{l}\hat{m}_{t+h \mid t} \\
\hat{\mu}_{t+h \mid t}-\hat{m}_{t+h \mid t} \\
\hat{\sigma}_{t+h \mid t}^{2}\end{array}$} & 1.52 & 0.85 & 0.67 & & \\
\hline & 0.00 & 0.03 & 0.09 & & \\
\hline & 0.01 & 0.02 & 0.05 & & \\
\hline
\end{tabular}

plots in figure 2 suggest a lack of information content, because they are not upward sloping. In contrast, the regression lines for $h=2$ and $h=4$ for the Riksbank are upward sloping, but the scatter plots indicate that there is considerable uncertainty about these slopes. Finally, the line computed for the entire sample of risk forecasts is slightly downward sloping.

In table 2, we provide summary statistics for the forecast data of the BoE and the Riksbank. While the sample averages of the difference between mean and mode forecasts increase with the forecast horizon, they remain very close to zero. The sample averages of the 
Figure 3. Plots of the Differences between the Mean Forecast and the Mode Forecast for the Bank of England and the Sveriges Riksbank

$\mathrm{BoE}, h=0$

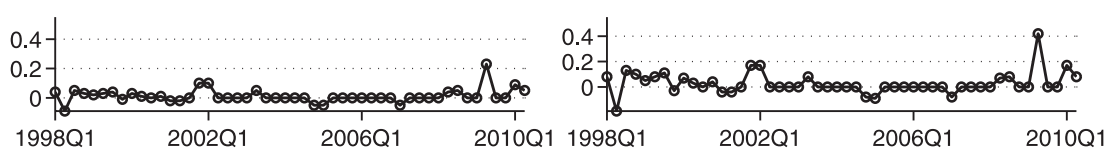

BoE, $h=4$

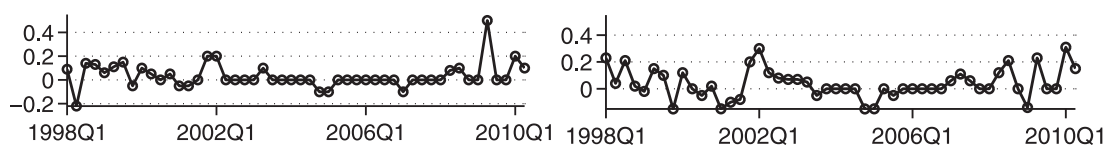

BoE, $h=8$

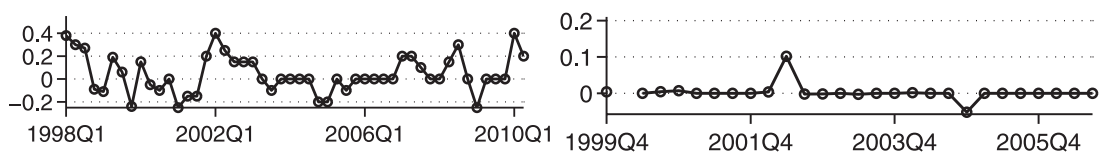

Riksbank, $h=2$
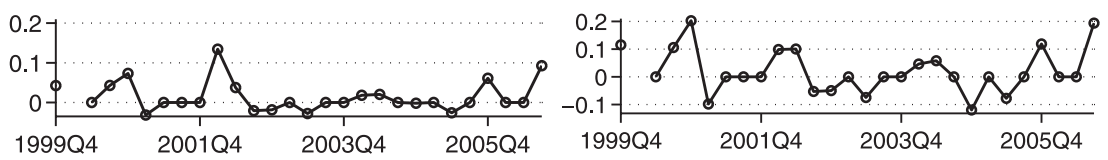

forecast variance grow substantially with the horizon, indicating the increasing forecast uncertainty. While the interquartile ranges for the forecasts of mean-mode differences and variances also increase with the forecast horizon, for the mode forecasts they do not. The latter finding is, of course, due to the fact that the long-run inflation point forecasts tend to be close to the inflation target.

Figure 3 shows the differences between mean and mode forecasts. It reveals that serial correlation in these differences seems to be fairly contained. In contrast, there are pronounced correlations across horizons. ${ }^{30}$

\footnotetext{
${ }^{30}$ This can also be seen in tables 7 and 8 .
} 


\subsection{Bias Tests}

As explained in Knüppel and Schultefrankenfeld (2011), when applying the framework of regression-based tests for forecast optimality as proposed by Mincer and Zarnowitz (1969) to risk forecasts, estimates of the intercept and the slope coefficient might be biased since the forecast data used to construct the Pearson mode skewness might themselves be biased.

Testing for a bias of the mean forecasts is interesting in itself. In addition, if the mean forecast $\hat{\mu}_{t+h \mid t}$ is biased, the squared forecast error of the mean, $\left(y_{t+h}-\hat{\mu}_{t+h \mid t}\right)^{2}$, is unlikely to be a good measure for the variance of inflation realization $y_{t+h}$. Therefore, it is useful to test whether an estimate of the intercept $c$ in the equation

$$
y_{t+h}-\hat{\mu}_{t+h \mid t}=c+\varepsilon_{t+h}
$$

is equal to zero. If the true variances - and hence the true standard deviations $\sigma_{t+h}$-are, on average, smaller than $\hat{\sigma}_{t+h \mid t}$, estimates of intercept and slope in a Mincer-Zarnowitz-type regression for risk forecasts are biased towards zero. ${ }^{31}$ Conversely, if $\sigma_{t+h}$ is larger than $\hat{\sigma}_{t+h \mid t}$, the estimates of intercept and slope are biased away from zero. Thus, it is important to test for unbiasedness of the volatility forecasts, too. Analogously to above, in the equation

$$
\left(y_{t+h}-\hat{\mu}_{t+h \mid t}\right)^{2}-\hat{\sigma}_{t+h \mid t}^{2}=c+\varepsilon_{t+h},
$$

we conduct a test for the null that $c=0 .^{32}$

In both equations (1) and (2), $\varepsilon_{t+h}$ denotes a zero-mean error term which is potentially subject to serial correlation. We address this issue by using Newey-West (1987) standard errors and prewhitening as suggested by Andrews and Monahan (1992). The truncation lags are chosen based on the procedure of Andrews

\footnotetext{
${ }^{31}$ The corresponding regression equation (3) can be found in the following section.

${ }^{32} \mathrm{We}$ also conducted bias tests for the mode forecast (under the potentially restrictive assumption of balanced risks on average) and the average balance of forecast risks. In both cases we could not reject the null of no bias for any forecast horizon.
} 


\section{Table 3. Tests for Bias of Forecast Mean and Forecast Variance}

\begin{tabular}{|c|c|c|c|c|c|}
\hline$h$ & 0 & 2 & 4 & 6 & 8 \\
\hline \multicolumn{6}{|c|}{ Bank of England } \\
\hline$T$ & 50 & 48 & 46 & 44 & 42 \\
\hline Mean & $\begin{array}{c}0.02 \\
(0.02)\end{array}$ & $\begin{array}{c}0.14 \\
(0.12)\end{array}$ & $\begin{array}{c}0.27 \\
(0.26)\end{array}$ & $\begin{array}{c}0.25 \\
(0.30)\end{array}$ & $\begin{array}{c}0.11 \\
(028)\end{array}$ \\
\hline Variance & -0.05 & 0.13 & 0.38 & 0.24 & 0.01 \\
\hline & $(0.03)$ & $(0.11)$ & $(0.32)$ & $(0.38)$ & $(0.39)$ \\
\hline \multicolumn{6}{|c|}{ Sveriges Riksbank } \\
\hline$T$ & 27 & 27 & 27 & & \\
\hline Mean & -0.04 & -0.01 & -0.24 & & \\
\hline & $(0.04)$ & $(0.19)$ & $(0.29)$ & & \\
\hline \multirow[t]{2}{*}{ Variance } & $-0.05 * *$ & 0.13 & 0.02 & & \\
\hline & $(0.01)$ & $(0.17)$ & $(0.16)$ & & \\
\hline
\end{tabular}

(1991). For the above and all other tests in this study, we employ the conventional significance level of 5 percent.

The results in table 3 show that all mean forecasts and all but one of the volatility forecasts are unbiased. The Riksbank's variance nowcast is an exception, showing a significant overprediction of volatility.

\section{Methodology}

The evaluation of risk forecasts will be based on tests for risk-forecast optimality and informativeness as discussed in Knüppel and Schultefrankenfeld (2011). In order to conduct such tests, a measure for the asymmetry of the forecast density has to be selected. Knüppel and Schultefrankenfeld (2011) find that the above-mentioned Pearson mode skewness is strongly preferable to the standard third-momentbased skewness, because the latter implies a very low power of the tests. As briefly stated above, the Pearson mode skewness of 
a random variable $Y$ is given by $(E[Y]-m) / \sigma$, where $E[Y]$ is the expectation, $m$ is the mode, and $\sigma$ is the standard deviation of $Y$.

Given a forecast horizon $h$, risk forecasts can be evaluated using the OLS regression equation

$$
\frac{y_{t+h}-\hat{m}_{t+h \mid t}}{\hat{\sigma}_{t+h \mid t}}=\alpha+\beta \frac{\hat{\mu}_{t+h \mid t}-\hat{m}_{t+h \mid t}}{\hat{\sigma}_{t+h \mid t}}+\varepsilon_{t+h}, \quad t+h=1,2, \ldots, T,
$$

where the error term $\varepsilon_{t+h}$ has an expectation of zero, and intercept $\alpha$ and slope $\beta$ are the coefficients to be estimated. $T$ denotes the sample size.

As stated above, the term $\left(\hat{\mu}_{t+h \mid t}-\hat{m}_{t+h \mid t}\right) / \hat{\sigma}_{t+h \mid t}$ on the righthand side is simply the risk forecast for period $t+h$, made in period $t$, where risk is measured by the Pearson mode skewness. On the left-hand side, $\left(y_{t+h}-\hat{m}_{t+h \mid t}\right) / \hat{\sigma}_{t+h \mid t}$ is the measure of realized risk, being equal to the scaled mode forecast error. It would be preferable to use $\left(y_{t+h}-m_{t+h \mid t}\right) / \sigma_{t+h \mid t}$ as the measure of realized risk, where $m_{t+h \mid t}$ and $\sigma_{t+h \mid t}$ are the true values of mode and standard deviation of the forecast variable in period $t+h$, conditional on information available to the forecaster in period $t$, but these quantities are, of course, unknown. However, as long as $\hat{m}_{t+h \mid t}$ and $\hat{\sigma}_{t+h \mid t}$ are unbiased forecasts of $m_{t+h \mid t}$ and $\sigma_{t+h \mid t}$, no major complications arise.

If $\hat{m}_{t+h \mid t}$ is biased, $\hat{\alpha}$, the estimate of the intercept $\alpha$, will be biased as well, but the slope $\beta$ will continue to be estimated consistently by $\hat{\beta} .^{33}$ If $\hat{\sigma}_{t+h \mid t}$ is biased, $\hat{\beta}$ will also be biased.

Assuming that $\hat{m}_{t+h \mid t}$ and $\hat{\sigma}_{t+h \mid t}$ are unbiased, it should not be possible to reject the joint hypothesis $\alpha=0, \beta=1$ if the risk forecasts are optimal, resembling the hypothesis for mean forecast optimality used by Mincer and Zarnowitz (1969). However, potential biases of $\hat{m}_{t+h \mid t}$ and $\hat{\sigma}_{t+h \mid t}$ suggest a slightly different approach. Knüppel and Schultefrankenfeld (2011) recommend checking for a potential bias of $\hat{\sigma}_{t+h \mid t}$ first and focusing on the single hypothesis $\beta=1$ due to its robustness with respect to biased mode forecasts. A complementing test of $\alpha=0$ can be useful, but a rejection does not

\footnotetext{
${ }^{33}$ In the remainder of the paper, a hat over a character always denotes the estimate or the forecast of the corresponding parameter. Whether the object is a forecast or an estimate will be clear from the context.
} 
necessarily imply non-optimality of the risk forecasts, since it could be caused by biased mode forecasts.

If the risk forecasts contain useful information, one should expect a rejection of the hypothesis $\beta=0$. If the test does not reject this hypothesis, there is no statistical evidence against a lack of information content. In view of the excerpt from Leeper (2003) cited at the beginning of this paper, this test, which checks for a systematic connection between forecast risks and realized risks, could actually be considered the most important one.

Although the tests have a much greater power if the Pearson mode skewness is used instead of the standard skewness as the measure of asymmetry, their power can still be expected to be fairly low in our empirical application. ${ }^{34}$ This is due to several reasons. Firstly, our samples of risk forecasts are rather small. Moreover, the magnitude of the forecast risks is, at best, moderate. The smaller these magnitudes are, however, the more difficult the inference about $\beta$ becomes. In addition, the fact that $m_{t+h \mid t}$ and $\sigma_{t+h \mid t}$ are unknown also contributes to the tests' low power, even if $\hat{m}_{t+h \mid t}$ and $\hat{\sigma}_{t+h \mid t}$ are unbiased forecasts. Finally, the potential serial correlation of the error terms also reduces power.

In order to alleviate these problems, in this analysis the quantitative risk forecasts will be investigated in a panel setup, where all forecast horizons are analyzed simultaneously and where, in addition to the serial correlation, the cross-correlation of the error terms is taken into account. The cross-correlation is caused by the fact that, for example, if $y_{t}$ is far from its unconditional mean, it is very likely that the realized risks, i.e., the scaled mode forecast errors associated with $y_{t}$, are large for all but the short forecast horizons. For the panel estimation, we use the approach described in Greene (1997, p. 687). This approach can also be applied to unbalanced panels, which allows us to use all of the BoE's risk-forecast data. In a first step, the Prais-Winsten transformation is employed to remove

\footnotetext{
${ }^{34}$ Using standard skewness, the forecast risk would be given by $E\left[\left(Y_{t+h \mid t}-\right.\right.$ $\left.\left.\hat{\mu}_{t+h \mid t}\right)^{3}\right] / \hat{\sigma}_{t+h \mid t}^{3}$ and the proxy for the realized risk by $\left(y_{t+h}-\hat{\mu}_{t+h \mid t}\right)^{3} / \hat{\sigma}_{t+h \mid t}^{3}$. $E\left[\left(Y_{t+h \mid t}-\hat{\mu}_{t+h \mid t}\right)^{3}\right]$ would be calculated based on the forecast density of the random variable $Y_{t+h \mid t}$.
} 
autocorrelation. Then the transformed data are analyzed using the seemingly unrelated regressions model. ${ }^{35}$

As described above, many central banks do not publish quantitative, but only qualitative, risk forecasts, giving assessments about the direction of the forecast risk. It is therefore important to evaluate direction-of-risk forecasts as well, even if the corresponding tests can be expected to suffer from lower power than those for the quantitative risk forecasts. ${ }^{36}$ The evaluation here is based on the categorical variables $q_{t+h}$ and $\hat{q}_{t+h \mid t}$, determined by the quantitative risk forecasts and realizations, where $q_{t+h}$ is related to the direction of the realized risk by

$$
q_{t+h \mid t}=\left\{\begin{array}{cl}
1 & \text { if } y_{t+h}>\hat{m}_{t+h \mid t} \\
0 & \text { if } y_{t+h}<\hat{m}_{t+h \mid t} \\
n a & \text { if } \hat{\mu}_{t+h \mid t}=\hat{m}_{t+h \mid t}
\end{array}\right.
$$

and $\hat{q}_{t+h \mid t}$ is related to the direction of the forecast risk by

$$
\hat{q}_{t+h \mid t}=\left\{\begin{array}{cl}
1 & \text { if } \hat{\mu}_{t+h \mid t}>\hat{m}_{t+h \mid t} \\
0 & \text { if } \hat{\mu}_{t+h \mid t}<\hat{m}_{t+h \mid t} \\
n a & \text { if } \hat{\mu}_{t+h \mid t}=\hat{m}_{t+h \mid t}
\end{array}\right.
$$

where na denotes a missing value which will be excluded from the analysis. Then, if $q_{t+h \mid t}=\hat{q}_{t+h \mid t}$, the direction-of-risk forecast is successful, and if $q_{t+h \mid t} \neq \hat{q}_{t+h \mid t}$, it is not.

In order to construct variables without missing values, we use the transformations

$$
\begin{aligned}
& \mathbf{q}_{h}^{N}=\mathbf{A}_{h} \mathbf{q}_{h}^{T}, \\
& \hat{\mathbf{q}}_{h}^{N}=\mathbf{A}_{h} \hat{\mathbf{q}}_{h}^{T},
\end{aligned}
$$

\footnotetext{
${ }^{35}$ Note that there is a minor error in the formula (15-57) by Greene (1997, p. $687)$. For the construction of the final covariance matrix of the errors, the covariance matrices of $A R(1)$ processes as defined in formula (13-10) are required. When estimating the covariances of the errors, we make use of the entire unbalanced sample in the case of the BoE. This approach is commonly attributed to Wilks (1932). Note that this approach does not necessarily produce a positivesemidefinite covariance matrix. Using only the balanced sample for the covariance estimation leaves the results virtually unchanged.

${ }^{36}$ However, tests based on direction-of-risk forecasts might be more reliable in the event of outliers or severe problems with the forecasts of $\sigma_{t+h}$.
} 
where the vector $\mathbf{q}_{h}^{T}$ is given by $\mathbf{q}_{h}^{T}=\left(q_{1+h \mid 1}, q_{2+h \mid 2}, \ldots, q_{T+h \mid T}\right)^{\prime}$, the vector $\hat{\mathbf{q}}_{t+h \mid t}$ is given by $\hat{\mathbf{q}}_{t+h \mid t}=\left(\hat{q}_{1+h \mid 1}, \hat{q}_{2+h \mid 2}, \ldots, \hat{q}_{T+h \mid T}\right)^{\prime}$, and $\mathbf{A}_{h}$ is a known $(N \times T)$ selection matrix consisting of 1's and 0 's, and with $N \leq T$. $\mathbf{A}_{h}$ is chosen such that the vectors $\mathbf{q}_{h}^{N}$ and $\hat{\mathbf{q}}_{h}^{N}$ do not contain missing values. ${ }^{37}$

Denoting the elements of $\mathbf{q}_{h}^{N}$ and $\hat{\mathbf{q}}_{h}^{N}$ by $q_{n+h \mid n}$ and $\hat{q}_{n+h \mid n}$, respectively, with $n=1,2, \ldots, N$, we test for the optimality of the direction-of-risk forecasts based on the regression

$$
q_{n+h \mid n}=\alpha_{q}+\beta_{q} \hat{q}_{n+h \mid n}+\varepsilon_{n+h} .
$$

Optimal risk forecasts imply neither $\beta_{q}=1$ nor $\alpha_{q}=0$, as explained in Knüppel and Schultefrankenfeld (2011). However, a necessary condition for forecast optimality is given by the inequality $\beta_{q}>0$. While a test of this inequality should not reject in the case of optimal forecasts, the hypothesis $\beta_{q}=0$ should be rejected. The hypothesis $\beta_{q}=$ 0 implies that the direction-of-risk forecasts are not informative. ${ }^{38}$

\section{Analysis of Risk Assessments}

\subsection{Quantitative Assessments}

In table 4, the results of the tests for risk-forecast optimality are shown for the even forecast horizons of both central banks, respectively. Note that the Riksbank forecast unbalanced risks only in about half of its forecasts. The same holds for the BoE for nowcasts and forecasts up to one year ahead. For longer forecast horizons, the share of unbalanced risk forecasts equals about two-thirds. Interestingly, the estimates of $\beta$ are negative for horizons $h=0,4,6$ in the case of the BoE, while the Riksbank's slope coefficients are

\footnotetext{
${ }^{37}$ If there are no missing values, $\mathbf{A}_{h}$ is a $(T \times T)$ identity matrix. If, for example, only the risk forecast for the first forecast of horizon $h$ is balanced, i.e., in the case of $\hat{\mu}_{1+h \mid 1}=\hat{m}_{1+h \mid 1}, N$ equals $T-1$ and $\mathbf{A}_{h}$ is given by $\mathbf{A}_{h}=\left[\begin{array}{ll}\mathbf{0}_{N} & \mathbf{I}_{N}\end{array}\right]$, where $\mathbf{0}_{N}$ denotes an $(N \times 1)$ vector of 0 's and $\mathbf{I}_{N}$ denotes the $(N \times N)$ identity matrix.

${ }^{38}$ In principle, tests based on the binomial distribution could be used for direction-of-risk forecasts, but the potential serial correlation of $\varepsilon_{n+h}$ renders the regression-based approach presented here more appealing for our investigations.
} 
Table 4. Panel-Based Tests for Bias, Informativeness, and Optimality of Quantitative Risk Forecasts of the Bank of England and the Sveriges Riksbank

\begin{tabular}{|c|c|c|c|c|c|}
\hline$h$ & 0 & 2 & 4 & 6 & 8 \\
\hline \multicolumn{6}{|c|}{ Bank of England } \\
\hline \multirow{3}{*}{$\begin{array}{l}T \\
N\end{array}$} & 50 & 48 & 46 & 44 & 42 \\
\hline & 24 & 22 & 22 & 30 & 28 \\
\hline & \multicolumn{5}{|c|}{ Coefficient Estimates } \\
\hline Intercept & $\begin{array}{c}0.09 \\
(0.10)\end{array}$ & $\begin{array}{c}0.19 \\
(0.17)\end{array}$ & $\begin{array}{c}0.33 \\
(0.18)\end{array}$ & $\begin{array}{c}0.24 \\
(0.19)\end{array}$ & $\begin{array}{c}-0.09 \\
(0.18)\end{array}$ \\
\hline \multirow[t]{2}{*}{ Slope } & $\begin{array}{c}-0.45 \\
(0.61)\end{array}$ & $\begin{array}{c}0.13 \\
(0.26)\end{array}$ & $\begin{array}{c}-0.52 \\
(0.21)\end{array}$ & $\begin{array}{c}-0.30 \\
(0.26)\end{array}$ & $\begin{array}{c}0.71 \\
(0.21)\end{array}$ \\
\hline & \multicolumn{5}{|c|}{ p-values } \\
\hline Bias & 0.376 & 0.253 & 0.066 & 0.209 & 0.621 \\
\hline Informativeness & 0.465 & 0.619 & 0.017 & 0.267 & 0.002 \\
\hline Optimality & 0.021 & 0.002 & 0.000 & 0.000 & 0.173 \\
\hline \multicolumn{6}{|c|}{ Sveriges Riksbank } \\
\hline \multirow{3}{*}{$\begin{array}{l}T \\
N\end{array}$} & 27 & 27 & 27 & & \\
\hline & 13 & 15 & 15 & & \\
\hline & \multicolumn{5}{|c|}{ Coefficient Estimates } \\
\hline Intercept & $\begin{array}{c}-0.09 \\
(0.13)\end{array}$ & $\begin{array}{c}-0.07 \\
(0.38)\end{array}$ & $\begin{array}{c}-0.31 \\
(0.31)\end{array}$ & & \\
\hline \multirow[t]{2}{*}{ Slope } & $\begin{array}{c}1.08 \\
(1.68)\end{array}$ & $\begin{array}{c}1.64 \\
(2.02)\end{array}$ & $\begin{array}{c}0.47 \\
(1.05)\end{array}$ & & \\
\hline & \multicolumn{5}{|c|}{ p-values } \\
\hline Bias & 0.513 & 0.855 & 0.336 & & \\
\hline Informativeness & 0.529 & 0.425 & 0.656 & & \\
\hline Optimality & 0.965 & 0.755 & 0.618 & & \\
\hline \multicolumn{6}{|c|}{$\begin{array}{l}\text { Notes: Figures in parentheses are standard errors. } T \text { denotes the sample. } N \text { denote } \\
\text { the number of forecasts with unbalanced risks. The row "Bias" refers to tests for } \\
\alpha=0 \text {, "Informativeness" to tests for } \beta=0 \text {, and "Optimality" to tests for } \beta=1 \text { in } \\
\text { equation (3). }\end{array}$} \\
\hline
\end{tabular}


all positive. The standard errors for the slope are often smaller for longer horizons than for shorter ones. This is due to the fact that the cross-correlations of the error terms are especially pronounced for longer forecast horizons.

For both the BoE and the Riksbank, we cannot reject the null that the estimated intercept $\hat{\alpha}$ is equal to zero at the 5 percent level. This means that there is no significant bias issue for any forecast horizon. In the case of the BoE, the $p$-values for the single null of optimality, i.e., for tests of $\beta=1$, indicate rejections for all horizons but $h=8$. The results of the joint null hypothesis of risk-forecast optimality $\alpha=0, \beta=1$, which are not reported in the table, tend to confirm this finding, with rejections for all forecast horizons except $h=0$ and $h=8$. The hypothesis of no information content is only rejected for the horizons $h=4$ and $h=8$, as shown by the $p$-values for informativeness. However, $\hat{\beta}$ is negative for $h=4$, which means that this rejection does not appear very plausible, because it would imply an adverse informative value. For the Riksbank, the estimation uncertainty turns out to be very large, so that no hypothesis about the slope $\beta$ can be rejected. Put differently, we cannot make clear statements with respect to the hypotheses of informativeness and of optimality, because the confidence intervals for the slope $\beta$ contain zero and unity likewise.

The results for the BoE strongly indicate that its risk forecasts are not optimal and that there is no systematic connection between realized risks and forecast risks. The only potential exception is the forecast horizon $h=8$. However, it does not appear too convincing that the properties of the risk forecasts just for the horizon $h=8$ should be so different from the other horizons. ${ }^{39}$ Moreover, a horizonspecific regression yields a negative estimate of $\beta$ for $h=8$, as also suggested by figure 2. Based on this estimate and its Newey-West standard error, one would reject the optimality hypothesis, $\beta=1$,

\footnotetext{
${ }^{39}$ For the neighboring horizon $h=7$, the estimated slope $\hat{\beta}$ equals 0.1 with a standard error of 0.2 , which means that the null of optimality is rejected, while the null of non-informativeness is not. The same results are obtained for all other odd horizons except for $h=5$, where, as in the case of $h=4, \hat{\beta}$ is significantly negative.
} 
but not the hypothesis of no informativeness, $\beta=0 .{ }^{40}$ The results for $h=8$ are therefore rather unclear.

The results for the Riksbank do not provide evidence against the hypothesis that risk forecasts and realized risks are unrelated at all forecast horizons. However, this result could also be caused by the small sample size, which strongly hampers inference. ${ }^{41}$

\subsection{Direction-of-Risk Assessments}

Since we are not aware of approaches for analyzing categorical data with potentially autocorrelated residuals in a panel setup, in the following analysis each forecast horizon is investigated separately. The results of the analysis of direction-of-risk forecasts are reported in table 5. When recoding the data according to equations (4) and (5), and selecting only observations with corresponding non-zero risk forecasts according to (6), we are left with, at most, thirty observations per forecast horizon. The estimates for the intercept $\alpha_{q}$ are unrelated to forecast optimality and are only reported for information. Note that, according to Pesaran and Timmermann (2006), the problem of autocorrelation of the error terms in equations with categorical data like equation (7) can be addressed using Newey-West standard errors. ${ }^{42}$

The estimates for $\beta_{q}$ are negative in the case of the BoE, except for $h=8$, and positive in the case of the Riksbank. For the Riksbank, again, none of the null hypotheses can be rejected. For the BoE forecasts, a rejection of the hypothesis $\beta_{q}>0$ occurs for $h=6$, suggesting that the respective risk forecasts cannot be optimal. At the

\footnotetext{
${ }^{40}$ The horizon-specific estimate for $\beta$ equals -0.46 , its standard error being 0.62. It should be mentioned that for no other forecast horizon do the panel setup and the separate analysis of each horizon give such contradictory results; i.e., for no other forecast horizon, including the odd horizons not reported here, is one of the hypotheses $\beta=0$ or $\beta=1$ rejected in one setup and the other hypothesis rejected in the other setup. The same applies to the results for the Riksbank. In general, the standard errors are, of course, considerably larger when each horizon is analyzed separately, which makes inference rather difficult.

${ }^{41}$ We also ran an estimation with the very restrictive assumption that intercept $\alpha$ and slope $\beta$ are identical, respectively, across all horizons. Even in this case, no hypothesis of interest can be rejected.

${ }^{42}$ Since Pesaran and Timmermann (2006) do not address the possibility of prewhitening, we do not use it here. Apart from that, we employ the same approach as for the bias tests in section 3 .
} 
Table 5. Tests for Informativeness and Optimality of Direction-of-Risk Forecasts of the Bank of England and the Sveriges Riksbank

\begin{tabular}{|c|c|c|c|c|c|}
\hline$h$ & 0 & 2 & 4 & 6 & 8 \\
\hline \multicolumn{6}{|c|}{ Bank of England } \\
\hline \multirow[t]{2}{*}{$N$} & 24 & 22 & 22 & 30 & 28 \\
\hline & \multicolumn{5}{|c|}{ Coefficient Estimates } \\
\hline Intercept & $\begin{array}{c}0.57 \\
(0.15)\end{array}$ & $\begin{array}{c}0.86 \\
(0.11)\end{array}$ & $\begin{array}{c}0.71 \\
(0.17)\end{array}$ & $\begin{array}{c}0.60 \\
(0.11)\end{array}$ & $\begin{array}{c}0.42 \\
(0.16)\end{array}$ \\
\hline \multirow[t]{2}{*}{ Slope } & $\begin{array}{c}-0.10 \\
(0.18)\end{array}$ & $\begin{array}{c}-0.32 \\
(0.19)\end{array}$ & $\begin{array}{c}-0.38 \\
(0.24)\end{array}$ & $\begin{array}{c}-0.25 \\
(0.12)\end{array}$ & $\begin{array}{c}0.02 \\
(0.20)\end{array}$ \\
\hline & \multicolumn{5}{|c|}{ p-values } \\
\hline Informativeness & 0.571 & 0.104 & 0.126 & 0.039 & 0.919 \\
\hline Optimality & 0.286 & 0.052 & 0.063 & 0.020 & 0.541 \\
\hline \multicolumn{6}{|c|}{ Sveriges Riksbank } \\
\hline \multirow[t]{2}{*}{$N$} & 13 & 15 & 15 & & \\
\hline & \multicolumn{5}{|c|}{ Coefficient Estimates } \\
\hline Intercept & $\begin{array}{c}0.33 \\
(0.20)\end{array}$ & $\begin{array}{c}0.50 \\
(0.19)\end{array}$ & $\begin{array}{c}0.33 \\
(0.20)\end{array}$ & & \\
\hline \multirow[t]{2}{*}{ Slope } & $\begin{array}{c}0.10 \\
(1.34)\end{array}$ & $\begin{array}{c}0.06 \\
(0.26)\end{array}$ & $\begin{array}{c}0.11 \\
(0.18)\end{array}$ & & \\
\hline & \multicolumn{5}{|c|}{ p-values } \\
\hline Informativeness & 0.787 & 0.832 & 0.549 & & \\
\hline Optimality & 0.606 & 0.584 & 0.726 & & \\
\hline
\end{tabular}

same time, the null of no information content must be rejected. This result, however, does not seem very plausible due to the negative sign of the slope. For all other horizons - i.e., for $h=0,2,4,8$ - the $p$-values for the test for informativeness substantially exceed 0.05. Hence, there is no evidence against a lack of information content 
in the BoE's direction-of-risk forecasts at these horizons. Although the null of risk-forecast optimality is not rejected for $h=2$ and $h=4$, it should be noted that the respective $p$-values hardly exceed 5 percent. ${ }^{43}$

Interestingly, the best risk-forecast performance in the case of the BoE is again observed for $h=8$. However, even for this horizon, only 50 percent of the direction-of-risk forecasts were successful, which means that the qualitative risk-forecast performance rather tends to support the hypothesis of no information content for this horizon.

\subsection{Summary of Empirical Results}

Summing up the results for quantitative and direction-of-risk forecasts, for the BoE there is strong evidence against the optimality of risk forecasts for almost all forecast horizons. In contrast, there is no conclusive evidence against the hypothesis that risk forecasts and realized risks are unrelated at all forecast horizons. The latter result also holds for the Riksbank. Yet the results for the Riksbank are subject to great uncertainty, because with only seven years of data, an evaluation of macroeconomic risk forecasts can be extremely difficult.

Given the number of central banks which engage in risk forecasting and the resources which are devoted to it, the fact that risk forecasts and realized risks seem to lack a systematic connection might appear surprising. However, taking into account the often rather poor performance of macroeconomic forecasts even for first moments - i.e., point forecasts - except for short forecast horizons, it does not seem too implausible for macroeconomic forecasts of third moments to be unsuccessful.

\section{Reconsidering the Rationale for Risk Assessments}

In light of the results of the previous section, it is interesting to consider some of the reasons that are commonly mentioned in order to explain why macroeconomic risk forecasts are made.

\footnotetext{
${ }^{43}$ Moreover, for the horizons $h=1$ and $h=3$ not reported in the table, the null of risk-forecast optimality is rejected.
} 
The IMF (2008, pp. 42-43) offers four reasons for potential asymmetries of forecast densities. Firstly, non-linearities such as capacity constraints or the zero lower bound for interest rates might result in asymmetric forecast densities. Given the apparent lack of informativeness as shown by the evaluation results for the quantitative risk forecasts and the direction-of-risk forecasts, non-linearities either seemed to play no role in the samples under study, or the forecasters' understanding of these non-linearities is too limited to lead to successful risk forecasts. For example, while the zero lower bound for the policy rate is a popular motivation for asymmetric forecast densities, one could ask whether the effects of quantitative easing might not counteract the zero-lower-bound problem in such a way that the forecast density is actually close to symmetric even if the policy rate is at a very low level.

Secondly, the figures of the central forecast might already be fixed when sudden large changes in important variables such as oil prices or exchange rates occur. Due to time constraints, it might be infeasible to calculate a new central forecast and to adapt the often extensive explanatory notes that come with the central forecast. Nonetheless, it might be possible to adapt the asymmetry of the forecast density to reflect the new information. However, if risk forecasts were used to incorporate last-minute information into the forecast densities without having to change the central forecast, the risk forecast accuracy ought to have been higher than it was above, in particular at very short forecast horizons. So at least for the BoE and the Riksbank, it can be stated without much doubt that this reason for issuing risk forecasts does not matter.

Thirdly, forecasts are often based on "technical" assumptions, in many cases concerning exogenous variables. For example, exchange rates are commonly assumed to remain constant for all forecast horizons. If such an assumption is used for institutional reasons but the forecaster believes that the domestic currency will appreciate soon, the asymmetry of the forecast density can be employed to allow for this view. However, if "technical" assumptions are used in the forecasting processes of the $\mathrm{BoE}$ and the Riksbank, and risk forecasts are used as an attempt to improve upon the forecast accuracy implied by these assumptions, it seems that such an improvement is infeasible. Coming back to the example of constant exchange rates, 
the difficulties in beating the random-walk forecast are actually well known. ${ }^{44}$

The fourth reason concerns the possibility of biased forecasts. If recent forecast errors appear to be biased, maybe due to an undetected structural change, the forecaster might refrain from shifting the current central forecast. Instead, he might be inclined to issue an asymmetric forecast density in order to account for the potential bias. Such an attempted bias correction using risk forecasts has either not been carried out by the BoE and the Riksbank or was carried out but did not work as intended. However, it is not possible to assess the individual probability of these two explanations based on the results of the optimality tests.

In addition to the reasons mentioned by the IMF, experts' expectations about asymmetric shocks might be a further motivation for risk forecasting. For example, a forecaster could simply believe that, in a certain situation, positive shocks are more likely than negative shocks. ${ }^{45}$ The asymmetry of future shocks is apparently often assumed in the forecasts of central banks, but our results suggest that such assumptions might not be justified. Actually, the BoE gives some narrative support to this supposition. Referring to inflationary developments from 1997 to 1999, the BoE (2000, pp. 63-64) states:

In general, the modal inflation forecast has been closer to actual outturns than the mean projection. This is because the MPC judged the risks to the central projection to be on the upside, largely because of the risk that the sterling exchange rate might depreciate sharply. Up to 2000 Q2 this did not occur; indeed, the exchange rate tended to be higher than the central assumption.

\footnotetext{
${ }^{44}$ See, for instance, Meese and Rogoff (1983).

${ }^{45}$ Actually, this reason for risk forecasts is very common in the publications of central banks. Two examples read as follows: "Risks to this [inflation] outlook are fully confirmed to lie on the upside. These risks include the possibility of further rises in oil and agricultural prices, as well as of unanticipated increases in administered prices and indirect taxes" (ECB 2007, p. 55). "The balance of risks to the inflation outlook, relative to the central projection, lies on the upside, as the prospect of a faster exchange rate depreciation and the associated adjustment to the level of import prices is the dominant influence" (BoE 2002a, p. 49). It is unlikely that non-linear forecasting models are the motivations for assuming unbalanced risks in oil and agricultural prices or exchange rates. Moreover, the BoE apparently made no technical assumption with respect to exchange rates. Instead, the forecasters simply seem to anticipate an asymmetry of future shocks.
} 
Furthermore, minority views may lead to asymmetric forecast densities. In institutions where several decision makers have to agree on a single central forecast - as, for instance, the board members of the BoE have to - a minority of the decision makers may not agree with the central forecast decided upon by the majority. The view of the minority then can be accommodated by the asymmetry of the forecast density. If this is actually the case, the results shown above suggest that such minority views do not help to produce more accurate forecasts.

Finally, risk forecasts could also be employed as a (subtle) communication device. For example, if the forecasts of an inflationtargeting central bank are made conditional on future interest rates as expected by market participants, it is rather unlikely that the inflation forecast will deviate strongly from the target at the relevant policy horizon. If there were a strong deviation, this might cause market participants to believe that either the policy of the central bank has changed or that the central bank's assessment of the economic conditions strongly differs from their own assessment. Both possibilities are not very attractive for a central bank that seeks to be transparent and predictable. In order to signal the possibility of an unexpected increase in the policy rate, a central bank might therefore prefer to forecast an inflation rate that is only slightly above target and to add upward risks to this forecast. By doing so, the central bank's central forecast is basically in line with the forecasts of the market participants. At the same time, the central bank makes it clear that these forecasts are subject to uncertainty and that the materialization of certain risks considered to be likely by the central bank would require a policy response different than the one expected by the market. As the probabilities of these risks materializing will change over time, the market participants will adapt their interest rate expectations accordingly. However, Rasche and Thornton (2002) investigate the balance-of-risks statements of the Federal Reserve and find that these do not appear to be a crucial factor in the market expectations concerning the federal funds rate. ${ }^{46}$ The likelihood of the possibility that risk forecasts are being used

\footnotetext{
${ }^{46}$ However, the balance-of-risks statements supposedly had a different interpretation during that period. They were related to a loss function as suggested by Kilian and Manganelli (2007) rather than to asymmetries of forecast densities.
} 
as a communication device cannot be evaluated based on our riskforecast evaluation. However, if risk forecasts are used in this way, they should be positively correlated with the (small) deviations of the inflation forecasts from the target. However, for neither the BoE nor the Riksbank do we find evidence of positive correlations. ${ }^{47}$

\section{Conclusion}

Many central banks augment their point forecasts with assessments of the balance of risks. For virtually all of the central banks surveyed in this work, we actually find clear statements that the presence of unbalanced forecast risks corresponds to an asymmetry of forecast densities. Surprisingly, the point forecasts published almost always correspond to the modes of the forecast densities.

The risk forecasts are made and presented in a variety of ways. They can be quantitative as in the case of the BoE and the Riksbank, or qualitative, thus only indicating the direction of the balance of risks, as, for example, in the case of the Federal Reserve and the ECB. Risk forecasts can also be discussed without referring to the balance of risks, thereby just giving an idea of how the central forecast would change if a certain risk materialized. This is often the case, for instance, for the Reserve Banks of Australia and New Zealand. Apart from the verbal presentation of the (balance of) risks, balance-of-risks forecasts are frequently represented in potentially asymmetric fan charts.

Since the balance of risks is supposed to contain information about the asymmetries of the densities of the forecast variables, there should be a systematic connection between risk forecasts and realized risks, where the realized risks in our study correspond to the scaled mode forecast errors. Investigating the risk forecasts for inflation produced by the BoE and the Riksbank, we fail to find such a connection. While the results for the Riksbank could also be caused by the small sample size, the results for the BoE indicate relatively clearly that the risk forecasts do not provide the intended information. Instead, it seems that risk forecasts and forecast errors are

\footnotetext{
${ }^{47}$ Depending on the forecast horizon and the central bank being analyzed, the correlation coefficients range from about -0.2 to 0.2 . They are all insignificant.
} 
unrelated. This holds for both quantitative forecasts and directionof-risk forecasts. We therefore conclude that it seems questionable whether macroeconomic risk forecasts are meaningful.

If inflation is actually endogenous with respect to a central bank's risk forecast, then it could of course be that the estimation results presented are misleading. For instance, in case of an upward risk, economic agents could anticipate a risk of rising interest rates. In response to this risk, economic activity could be dampened, leading to lower demand and, consequently, to lower inflation. Then, even if the upward risk to inflation materialized, inflation could still be lower than forecast. However, if the endogeneity issue were empirically relevant, we would expect our estimated slope coefficients to decrease with the forecast horizon, because the endogeneity would tend to be less pronounced for shorter forecast horizons. Since there is no such decrease, the presence of an endogeneity problem appears unlikely. A deeper analysis of this issue, though, is left for future research.

However, two other caveats must also be mentioned. Firstly, the success of risk forecasts might depend on the variable under study. If, for example, output growth is best described by a regime-switching process as proposed by Hamilton (1989), it should be possible to issue informative risk forecasts for this variable. At least for short horizons, one would just have to forecast upward risks during recessions and downward risks during expansions. Secondly, if discrete random variables with few possible outcomes are an important determinant of the variable under study, risk forecasts could also perform well. One example might be a potential future change in the VAT rate and its effect on inflation. However, in such cases one might prefer to conduct scenario analyses, as the Riksbank has done since 2007. This has the additional advantage of clarifying the comovements between variables in the event of the risk materializing.

\section{Appendix 1. Central Banks' Statements on Risk Forecasting}

The following section cites the statements of central banks on which section 2 and table 1 are based. Table 6 contains the positions in these central banks' publications where their risk assessments can be found. 


\section{Table 6. Publications of Risk Assessments by Central Banks}

\begin{tabular}{|c|c|}
\hline Central Bank & Risk Assessments Published In \\
\hline Bank of Canada & $\begin{array}{l}\text { Monetary Policy Report, Chapter } \\
\text { "Risks to the Outlook" }\end{array}$ \\
\hline Banco Central de Chile & $\begin{array}{l}\text { Monetary Policy Report, Chapter } \\
\text { "Inflation Scenarios," Section } \\
\text { "Risk Scenarios" }\end{array}$ \\
\hline Bank of England & $\begin{array}{l}\text { Inflation Report, Chapter } \\
\text { "Prospects for Inflation," Section } \\
\text { "Key Judgements and Risk" }\end{array}$ \\
\hline Banco de España & $\begin{array}{l}\text { Economic Bulletin, Chapter } \\
\text { "Spanish Economic Projections } \\
\text { Report," Section "Risks to the } \\
\text { Projection" (Chapter Appears } \\
\text { Semi-Annually) }\end{array}$ \\
\hline Bank of Israel & $\begin{array}{l}\text { Inflation Report, Chapter "Update } \\
\text { of the Forecasts," Section } \\
\text { "Assessments Regarding the } \\
\text { Development of Inflation and the } \\
\text { Balance of Its Risks" }\end{array}$ \\
\hline Bank of Japan & $\begin{array}{l}\text { Outlook for Economic Activity and } \\
\text { Prices, Figure "Risk Balance } \\
\text { Charts" and Section "Upside and } \\
\text { Downside Risks" }\end{array}$ \\
\hline Banco de Portugal & $\begin{array}{l}\text { Economic Bulletin, Chapter } \\
\text { "Outlook for the Portuguese } \\
\text { Economy," Section "Uncertainty } \\
\text { and Risks" (Chapter Appears } \\
\text { Semi-Annually) }\end{array}$ \\
\hline $\begin{array}{l}\text { Board of Governors of the } \\
\text { Federal Reserve System }\end{array}$ & $\begin{array}{l}\text { Monetary Policy Report to the } \\
\text { Congress, Chapter "Summary of } \\
\text { Economic Projections," Section } \\
\text { "Uncertainty and Risks" }\end{array}$ \\
\hline Deutsche Bundesbank & $\begin{array}{l}\text { Monthly Report, Chapter "Outlook } \\
\text { for the German Economy," } \\
\text { Section "Risk Assessment" } \\
\text { (Chapter Appears } \\
\text { Semi-Annually) }\end{array}$ \\
\hline
\end{tabular}




\section{Table 6. (Continued)}

\begin{tabular}{|c|c|}
\hline Central Bank & Risk Assessments Published In \\
\hline European Central Bank & $\begin{array}{l}\text { Monthly Bulletin, "Editorial" and } \\
\text { "The Outlook for Economic } \\
\text { Activity" }\end{array}$ \\
\hline International Monetary Fund & $\begin{array}{l}\text { World Economic Outlook, Chapter } \\
\text { "Global Prospects and Policies" }\end{array}$ \\
\hline Magyar Nemzeti Bank & $\begin{array}{l}\text { Quarterly Report on Inflation, } \\
\text { Chapter "Inflation and Real } \\
\text { Economy Outlook," Section } \\
\text { "Inflation and Growth Risks" }\end{array}$ \\
\hline Norges Bank & $\begin{array}{l}\text { Monetary Policy Report, Chapter } \\
\text { "Monetary Policy Assessments } \\
\text { and Strategy," Section } \\
\text { "Uncertainty Surrounding the } \\
\text { Projections (Scenario Analyses)" }\end{array}$ \\
\hline Reserve Bank of Australia & $\begin{array}{l}\text { Statement on Monetary Policy, } \\
\text { Chapter "Economic Outlook," } \\
\text { Section "Risks" }\end{array}$ \\
\hline Reserve Bank of New Zealand & $\begin{array}{l}\text { Monetary Policy Statement, } \\
\text { Chapters "Overview and Key } \\
\text { Policy Judgements" and } \\
\text { "International Developments and } \\
\text { Outlook" }\end{array}$ \\
\hline Sveriges Riksbank (2007-Present) & $\begin{array}{l}\text { Monetary Policy Report, Chapter } \\
\text { "Alternative Scenarios and Risks } \\
\text { (Scenario Analyses)" }\end{array}$ \\
\hline Sveriges Riksbank (1999-2006) & $\begin{array}{l}\text { Inflation Report, Chapter "Inflation } \\
\text { Assessment," Section "Risk } \\
\text { Assessment" }\end{array}$ \\
\hline Swiss National Bank & $\begin{array}{l}\text { Quarterly Bulletin, Chapter } \\
\text { "Monetary Policy Report," } \\
\text { Section "SNB Inflation Forecast" }\end{array}$ \\
\hline
\end{tabular}

Bank of Canada

"The staff projection is an outlook for the economy's most likely path." 48

\footnotetext{
${ }^{48}$ See www.bankofcanada.ca/en/monetary/monetary_decision3.html.
} 
"While the underlying macroeconomic risks to the projection are roughly balanced, the Bank judges that, as a consequence of operating at the effective lower bound, the overall risks to its inflation projection are tilted slightly to the downside" (Bank of Canada 2009, p. 27).

"Chart 23 and Chart 24 depict the 50 per cent and 90 per cent confidence bands for year-over-year core and total CPI inflation. . . . In particular, they show the slight downward tilt to the confidence bands that results from monetary policy operating at the effective lower bound" 49 (Bank of Canada 2009, p. 26).

\section{Banco Central de Chile}

"Balance of risks: Evaluation of possible alternative scenarios to the baseline scenario used in projections (considered the most likely in the Monetary Policy Report) and their implications for future paths of output and inflation. The combined analysis of different sources of uncertainty to the baseline projection scenario are reflected in the balance of risks, which may be biased downward, upward or balanced, in terms of growth and inflation, as compared to the baseline scenario" (Banco Central de Chile 2007, p. 32).

"When the balance of risks around the central or modal projection slopes upward (positive bias), values above the modal projection are considered more likely to occur than values below it" (Banco Central de Chile 2001, p. 13).

\section{Bank of England}

"The central projection of inflation is then interpreted as being the 'mode' of the statistical distribution - it is the single most likely outcome based on current knowledge and judgment" (Britton, Fisher, and Whitley 1998, p. 32).

"In order to produce the fan chart, only one number is needed to summarise the degree of skewness (the balance of risks). . . The Bank's analysis focuses on the difference between the mean and the mode of the forecast distribution to be presented in the Report. This

\footnotetext{
${ }^{49}$ Note that this statement suggests that expected inflation is lower than the central projection of inflation. Moreover, it implies that the Bank of Canada produces quantitative risk forecasts.
} 
difference is of interest as a summary statistic of the balance of risks" (Britton, Fisher, and Whitley 1998, p. 32).

"If the MPC believed there was a higher probability that inflation would be above the mode than below, then the area under the curve would be skewed to the right" (Bank of England 2002b, p. 48).

\section{Banco de España}

"These factors ... suggest that the risks surrounding the output growth projections are on the low side. This means that downward deviations from the growth path of the central scenario of this report are considered more likely than upward ones" (Banco de España 2008, p. 4).

"A central projection scenario is obtained. . . This central scenario is considered the most likely" (Ortega et al. 2007, p. 19).

Bank of Israel

"Nonetheless, within the horizon of a year or more, the upside risks of inflation balance out with its downside risks" (Bank of Israel 2008, p. 26).

"The principal risk factor that could lead to the nonmaterialization of this forecast is the course of global developments" (Bank of Israel 2010, p. 36).

Bank of Japan

"Each Policy Board member submits his or her forecasts in the form of point estimates, the values to which he or she attaches the highest probability of realization. . . . Each Policy Board member also indicates, in the form of a probability distribution, the likelihood that upside or downside risks will materialize and cause divergence from the forecast value" (Bank of Japan 2008, p. 9).

"The probability distribution for the rate of real GDP growth in fiscal 2008 is skewed to the left. This suggests that Policy Board members consider the downside risks to be greater than the upside risks" (Bank of Japan 2008, p. 9).

Banco de Portugal

"Risks on economic activity are on the downside, particularly in 2011" (Banco de Portugal 2010, p. 10). 
"According to the quantification of risks, the likelihood that GDP growth may fall below the present outlook stands at 54 per cent in 2010 and 63 per cent in 2011" (Banco de Portugal 2010, p. 18).

"The baseline point forecasts are interpreted as the mode of the joint distribution" ${ }^{50}$ (Pinheiro and Esteves 2010, p. 1).

\section{Board of Governors of the Federal Reserve System}

"Participants also provide judgments as to whether the risks to their projections are weighted to the upside, downside, or are broadly balanced. That is, participants judge whether each variable is more likely to be above or below their projections of the most likely outcome" (Board of Governors of the Federal Reserve System 2008, p. 45).

"The projections now produced by FOMC participants are explicitly modal forecasts in that they represent participants' projections of the most likely outcome. Although participants provide qualitative assessments of whether the risks around their projections are weighted to one side or the other, we do not have quantitative estimates of any skew" (Reifschneider and Tulip 2007, p. 12).

"Most participants viewed the risks to their inflation projections as weighted to the upside. Recent sharp increases in energy and food prices and the passthrough of dollar depreciation into import prices could boost inflation in the near term by more than currently anticipated" (Board of Governors of the Federal Reserve System 2008, p. 41).

\section{Deutsche Bundesbank}

"It is generally assumed that uncertainties are distributed symmetrically around the most likely value, ie the baseline. Depending on the specific data situation and conditions, there may well be signs when the projections are produced that this will not be the case. Indeed, unlike in the historical patterns, there is often a skewed distribution. In this case, the terms upside or downside risks are used" (Deutsche Bundesbank 2007, p. 27).

\footnotetext{
${ }^{50}$ Note that this interpretation differs from those of most other central banks, which consider the marginal modes.
} 


\section{European Central Bank}

"Risks to the outlook for price developments are slightly tilted to the upside. They relate, in particular, to the evolution of energy and nonoil commodity prices. Furthermore, increases in indirect taxation and administered prices may be greater than currently expected" (European Central Bank 2010, p. 6).

"ECB/Eurosystem staff projections are presented in the form of ranges. The use of ranges acknowledges the inevitable uncertainty surrounding macroeconomic projections." 51

\section{International Monetary Fund}

"The IMF staff has presented risks to the WEO projections using a fan chart. . . . The methodology for constructing the fan chart is similar to that originally developed by the Bank of England. The central forecast is represented as the mode, or the most likely outcome. . . . The skewness of the distribution, or the relative size of the two pieces of the normal distribution, represents the balance of risks to the central forecast" (International Monetary Fund 2008, pp. 41-42).

"In the case of the balance of risk being tilted to the downside . . . the expected probability of outcomes being below the central forecast exceeds 50 percent" (International Monetary Fund 2006, p. 25).

\section{Magyar Nemzeti Bank}

"In order to plot the fan chart, the uncertainty distribution must be determined for each point in time on the projection horizon. . . . The mode of distribution is identical to the central projection. . . . In determining the skewness that indicates risk direction, the risk perception of the Economics Department prevails" (Magyar Nemzeti Bank 2004, p. 107).

"The method that we follow in preparing fan charts broadly corresponds to that of the Bank of England, and the same holds true for the Swedish method" (Magyar Nemzeti Bank 2004, p. 108).

\footnotetext{
${ }^{51}$ See www.ecb.int/pub/pdf/other/newprocedureforprojections200912en.pdf.
} 
"On the whole, our inflation forecast is apparently jeopardised by significant upward risks, which means that actual price increases will more likely exceed our expectations, rather than fall short of them" (Magyar Nemzeti Bank 2008, p. 46).

\section{Norges Bank}

"There is also a risk that the global downturn will be deeper and more prolonged than expected. . . . Overall, the outlook and balance of risks suggest that the key policy rate should be gradually reduced further to a level of around 1\% in the second half of 2009" (Norges Bank 2009, p. 13).

\section{Reserve Bank of Australia}

"It would be a mistake to focus only on the point forecast; it makes much more sense to think of the central forecast as simply the modal point on the distribution of the possible outcomes, with a sequence of progressively less likely outcomes on either side. Nor is that distribution necessarily symmetric - it may be skewed one way or the other. . . . We do not use fan charts per se, but we do try to consider alternative scenarios to the central forecast. We attempt to use the results of that process to articulate some sense of the balance of risks - both on the inflation outlook and on growth prospects - in the published statements." 52

"As always, there are risks in both directions around the forecasts, although overall, these risks are viewed as evenly balanced" (Reserve Bank of Australia 2010, p. 57).

\section{Reserve Bank of New Zealand}

"The central forecast is only one of a large number of potential outcomes for the economy, albeit the outcome that the Bank considers to be the most likely" (Conway 2000, p. 14).

"We continue to see the balance of risks to the central projection as being to the downside for activity and inflation" (Reserve Bank of New Zealand 2009, p. 4).

\footnotetext{
${ }^{52}$ See www.rba.gov.au/speeches/2001/sp-ag-101001.html.
} 


\section{Sveriges Riksbank (2007-Present)}

"The forecasts in the main scenario show the path which the Riksbank expects the economy to take and is a weighted consideration of various conceivable development paths (scenarios) and risks. [continued in footnote 11] There are therefore no grounds to revise the main scenario afterwards in light of a certain specific risk. This approach was adopted previously in the Inflation Report" (Sveriges Riksbank 2007, p. 22).

"The uncertainty bands for the forecasts for inflation and GDP growth are based on the Riksbank's historical forecast errors. [continued in footnote 12] This entails a change in the method used for designing the fan chart for inflation, which has previously been calculated using a weighted average of underlying risks. With the new method, the uncertainty bands are symmetrical" (Sveriges Riksbank 2007, p. 22).

\section{Sveriges Riksbank (1999-2006)}

"The distribution that is used as an approximation of the inflation forecast's distribution is known in statistical terminology as twopiece normal. . . . From Fig. B3 it will be seen that forecast inflation for the second quarter of 2000 carries a downside risk (the distribution in Fig. B3 is somewhat skewed to the left). The broken line is the inflation forecast in the main scenario (the mode)" (Sveriges Riksbank 1998, pp. 36-37).

"Skew is measured as the difference between the mean value and the most probable value (the mode of the distribution)" (Sveriges Riksbank 1998, p. 36).

"The overall assessment of different risks is that the probability of inflation being higher than in the main scenario is slightly greater than the probability of lower inflation" (Sveriges Riksbank 2006, p. 38).

\section{Swiss National Bank}

"The higher inflation expectations and the possibility of secondround effects will keep inflation risks on the upside" (Swiss National Bank 2008, p. 13). 
"Uncertainty about the future outlook for the global economy remains high, however, and downside risks predominate" (Swiss National Bank 2010c, p. 19).

\section{Appendix 2. Data Details}

\section{Bank of England}

As mentioned in section 3, the BoE and the Riksbank use the tpndistribution. The density of a tpn-distributed variable $Y$ is given by

$$
f(y)=\left\{\begin{array}{lll}
A \exp \left(-\frac{(y-m)^{2}}{2 \sigma_{1}^{2}}\right) & \text { if } & y \leq m \\
A \exp \left(-\frac{(y-m)^{2}}{2 \sigma_{2}^{2}}\right) & \text { if } & y \geq m
\end{array}\right.
$$

with $A=\frac{2}{\sqrt{2 \pi}\left(\sigma_{1}+\sigma_{2}\right)}$ and $m$ denoting the mode of the distribution. The more $\sigma_{1}$ differs from $\sigma_{2}$, the more asymmetric the distribution becomes. If $\sigma_{1}$ and $\sigma_{2}$ are identical, a normal distribution is obtained.

In order to determine the Pearson mode skewness, defined as the difference between the mean and the mode forecast, scaled by the forecast standard deviation, we have to calculate the variance, which is given by

$$
\sigma^{2}=\left(1-\frac{2}{\pi}\right)\left(\sigma_{2}-\sigma_{1}\right)^{2}+\sigma_{1} \sigma_{2}
$$

For this calculation three parameters of the BoE's forecast densities are required, which can be downloaded directly from the bank's web site. ${ }^{53}$ These parameters are the mean $\mu$, the mode $m$, and an uncertainty measure $\omega$. Following Wallis (2004), it is helpful to define

$$
s=\frac{\mu-m}{\omega},
$$

from which the quantity $\gamma$ can be determined as

$$
\gamma=\operatorname{sign}(s) \sqrt{1-4\left(\frac{\sqrt{1+\pi s^{2}}-1}{\pi s^{2}}\right)^{2}} .
$$

\footnotetext{
${ }^{53}$ See www.bankofengland.co.uk/publications/inflationreport/irprobab.htm.
} 
The standard deviations $\sigma_{1}$ and $\sigma_{2}$ can then be calculated as

$$
\sigma_{1}=\frac{\omega}{\sqrt{1+\gamma}}, \quad \sigma_{2}=\frac{\omega}{\sqrt{1-\gamma}}
$$

and can be inserted into the formula for the variance of the forecast density $\sigma^{2}$ given above. Then the Pearson mode skewness $(\mu-m) / \sigma$ can be determined. Its values are displayed in table 7 .

\section{Sveriges Riksbank}

There are two inflation fan charts in each Inflation Report we study. One chart refers to the price index CPI, the other to the price index UND1X. ${ }^{54}$ We focus on the CPI only. Forecast values are given for the current month and the next twenty-four months. The values which are published are the central forecast (mode forecast) and the quantiles belonging to the 50 percent, 75 percent, and 90 percent confidence intervals. Unlike the intervals published by the BoE, these intervals are symmetric around the median, as clarified by Blix and Sellin (2000, footnote 7).

In contrast to the BoE, the Riskbank does not publish the means and standard deviations of the tpn-distributions that underlie the fan charts. ${ }^{55}$ Therefore, we first have to back out the parameters of these distributions in order to calculate their means and standard deviations. The precision of the parameter estimates of course depends on the precision of the published forecast values. For Inflation Reports 1999:4 to 2004:4 they are very precise, having fourteen decimal places. Then, for the Inflation Reports 2005:1 and 2005:2, the published values have two decimal places. Finally, the published values have only one decimal place for Inflation Reports 2005:3 to 2006:3. Surprisingly, the mode forecasts from Inflation Report 2004:4 also have only one decimal place. Hence, while backing out the exact parameter values is relatively easy until at least Inflation

\footnotetext{
${ }^{54}$ The index UND1X is defined as the CPI excluding household mortgage interest expenditure and the direct effects of changes in indirect taxes and subsidies.

${ }^{55}$ The fact that the Riksbank uses a tpn-distribution is stated in Sveriges Riksbank (1998, pp. 36-37).
} 
Vol. 8 No. 3 How Informative Are Central Bank Assessments?

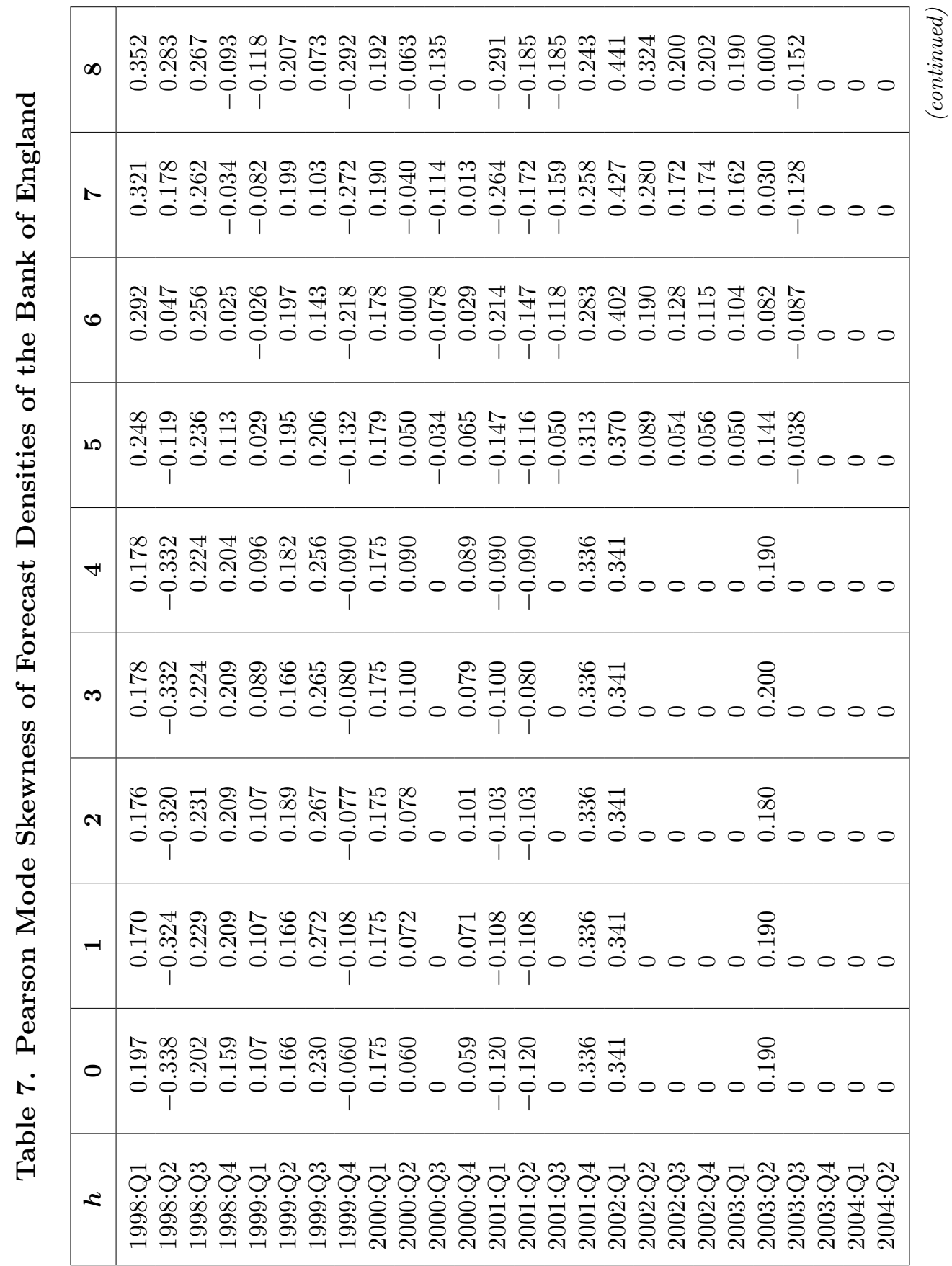




\begin{tabular}{|c|c|c|}
\hline$\infty$ & 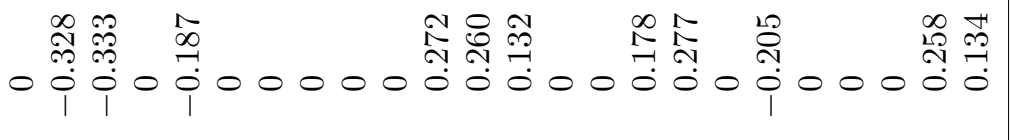 & 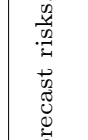 \\
\hline$\wedge$ & 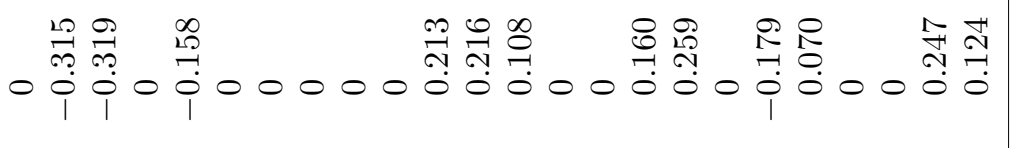 & 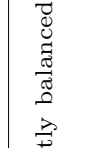 \\
\hline 0 & o & $\begin{array}{l}0 \\
0 \\
=\end{array}$ \\
\hline 10 & 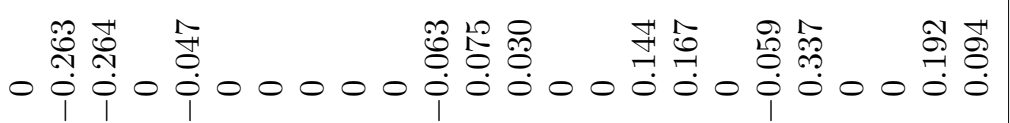 & 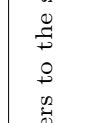 \\
\hline$\nabla^{\prime}$ & 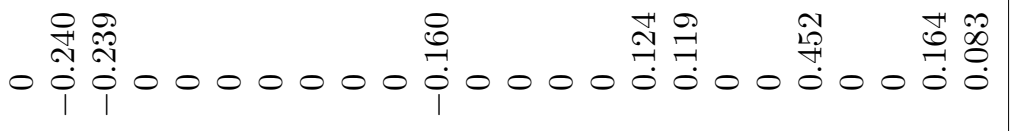 & 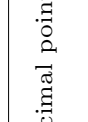 \\
\hline$\infty$ & 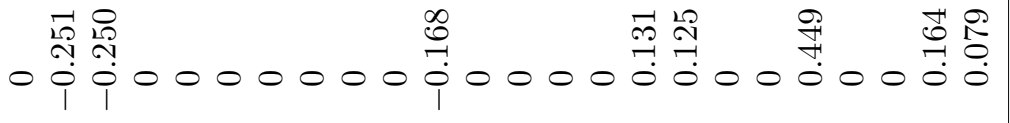 & 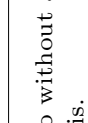 \\
\hline N & 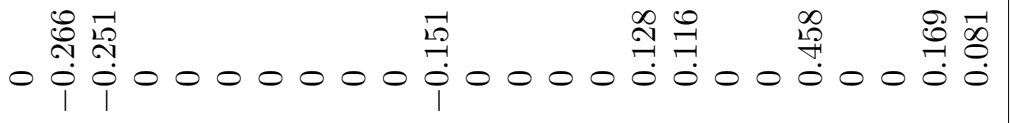 & 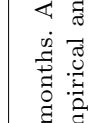 \\
\hline-1 & 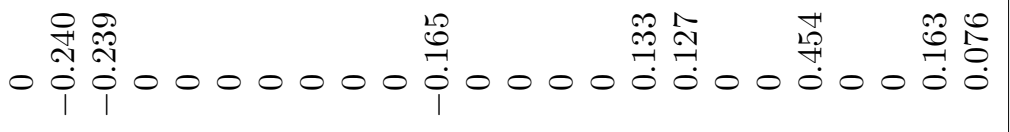 & 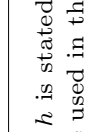 \\
\hline 0 & 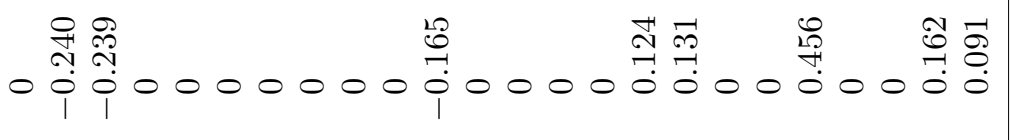 & $\begin{array}{l}V \\
=\end{array}$ \\
\hline$\simeq$ & 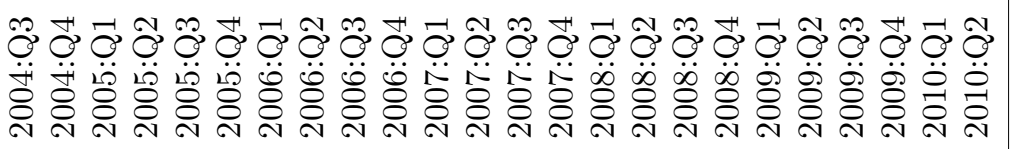 & 8 \\
\hline
\end{tabular}


Report 2004:3, the estimates can be expected to be less precise for the following Inflation Reports due to the rounding of the forecast values.

Backing out the parameter values requires fitting a tpndistribution to the modes and quantiles published. This fitting can be carried out using either a least-squares criterion or a likelihoodratio criterion as shown by García and Manzanares (2007). For forecasts from Inflation Reports 1999:4 to 2004:4, the differences between the results obtained with both criterions are small in general. But especially when only one decimal place is used, the differences can become larger. In these cases, the likelihood-ratio criterion gives more plausible results. For example, the skewness of the Riksbank's density forecasts published in a certain Inflation Report never changes sign from one forecast horizon to the next, ${ }^{56}$ i.e., the skewness might switch between zero and positive, or between zero and negative, but not between positive and negative. Looking at the Inflation Report 2005:4, however, with the least-squares criterion, the skewness for the five-month-ahead forecast is negative, while it is positive for four and six months ahead. With the likelihood-ratio criterion, the skewness is positive for four, five, and six months ahead. Therefore, we use the likelihood-ratio criterion to back out the parameters and to calculate the skewness of the inflation forecasts.

The skewness obtained in this way is cross-checked with the statements in the Inflation Reports. If an Inflation Report states that risks are balanced, we set the skewness of the corresponding forecast densities to zero, even if the estimated parameters indicate a (small) non-zero skewness. We do this because the parameter estimation results, as explained above, can be affected by imprecise data. The Pearson mode skewness for the selected forecast horizons is displayed in table 8 .

\footnotetext{
${ }^{56}$ This becomes clear when reading the chapters of the Inflation Reports that discuss the balance of risks.
} 


\begin{tabular}{|c|c|}
\hline$\vec{N}$ & 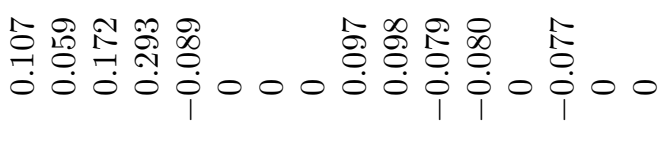 \\
\hline$\stackrel{\infty}{\sim}$ & 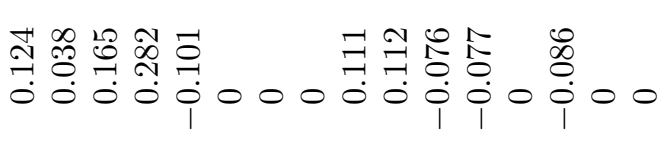 \\
\hline$\stackrel{12}{-}$ & 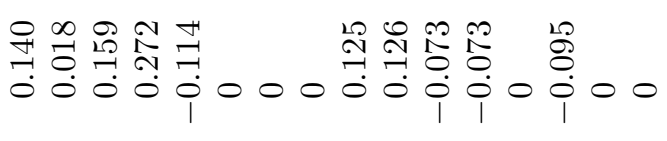 \\
\hline$\stackrel{\sim}{\sim}$ & 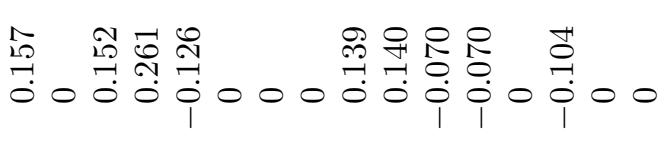 \\
\hline 0 & 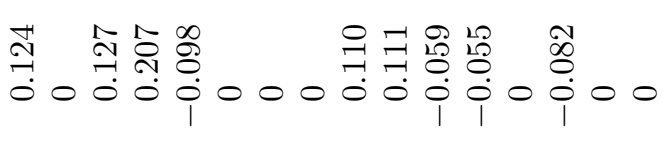 \\
\hline 0 & 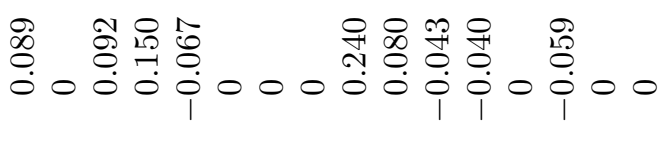 \\
\hline$\infty$ & 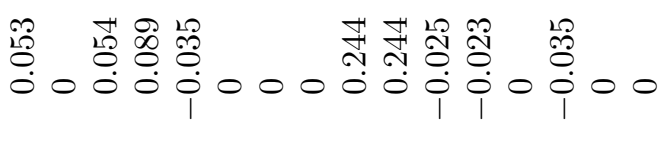 \\
\hline 0 & 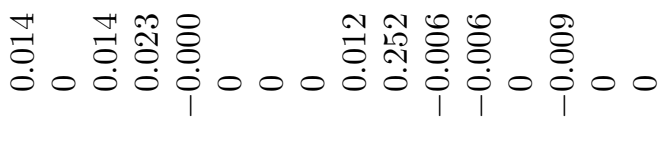 \\
\hline$\approx$ & 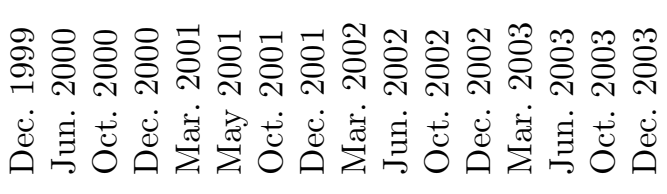 \\
\hline
\end{tabular}




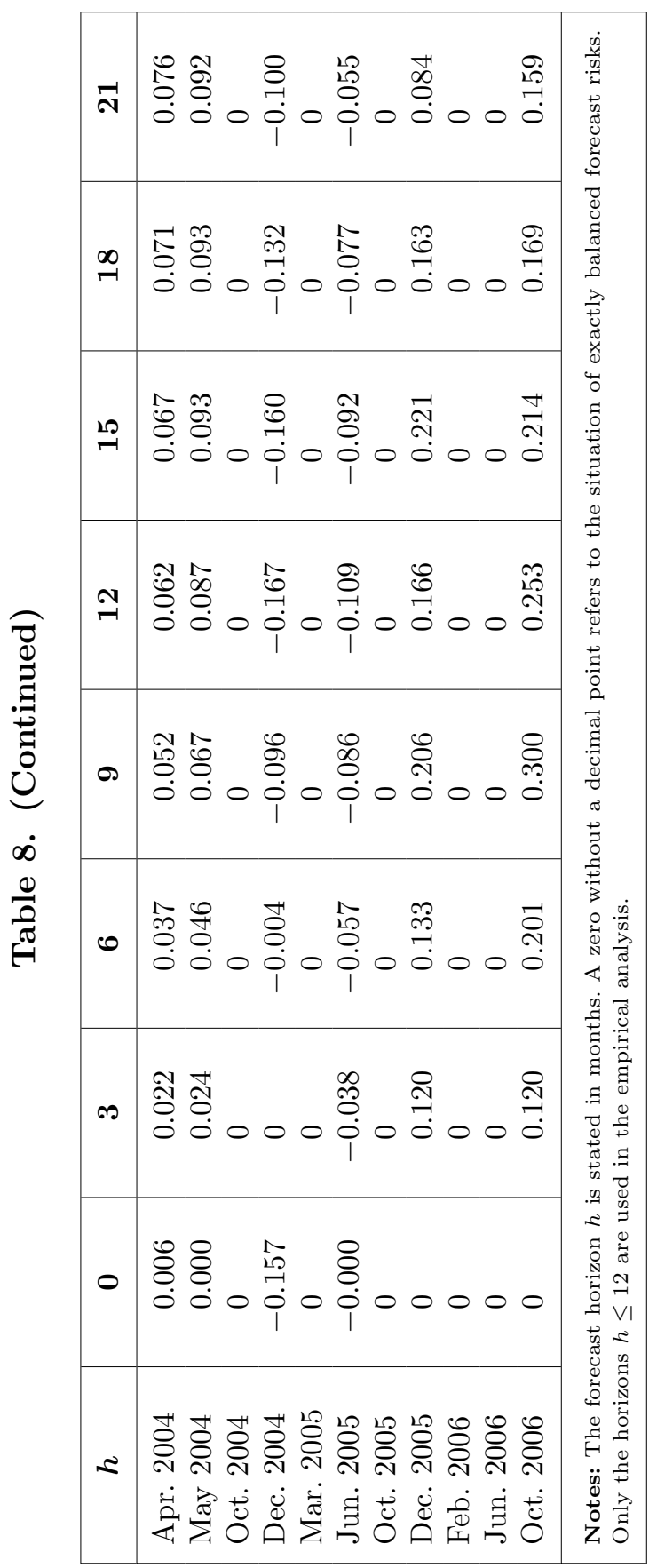




\section{References}

Andrews, D. W. K. 1991. "Heteroskedasticity and Autocorrelation Consistent Covariance Matrix Estimation." Econometrica 59 (3): $817-58$.

Andrews, D. W. K., and J. C. Monahan. 1992. "An Improved Heteroskedasticity and Autocorrelation Consistent Covariance Matrix Estimator." Econometrica 60 (4): 953-66.

Banco Central de Chile. 2001. "Monetary Policy Report" (January). 2007. "Monetary Policy in an Inflation Targeting Framework."

Banco de España. 2008. "Economic Bulletin." Chapter: "Spanish Economic Projections Report."

Banco de Portugal. 2010. "Economic Bulletin" (Summer).

Bank of Canada. 2009. "Monetary Policy Report" (October).

Bank of England. 2000. "Inflation Report" (August). 2002a. "Inflation Report" (February). 2002b. "Inflation Report" (May).

Bank of Israel. 2008. "Inflation Report" (April-June). 2010. "Inflation Report" (July-September).

Bank of Japan. 2008. "Outlook for Economic Activity and Prices" (April).

Blix, M., and P. Sellin. 1999. "Inflation Forecasts with Uncertainty Intervals." Quarterly Review (Sveriges Riksbank) 2: $12-28$.

- 2000. "A Bivariate Distribution for Inflation and Output Forecasts." Sveriges Riksbank Working Paper No. 102.

Board of Governors of the Federal Reserve System. 2008. "Monetary Policy Report to the Congress" (July).

Britton, E., P. Fisher, and J. Whitley. 1998. "The Inflation Report Projections: Understanding the Fan Chart." Quarterly Bulletin (Bank of England) (February): 30-37.

Conway, P. 2000. "Monetary Policy in an Uncertain World." Bulletin (Reserve Bank of New Zealand) 63 (3): 5-15.

Deutsche Bundesbank. 2007. "Monthly Report" (December). 2010. "Monthly Report" (June).

Diebold, F. X., and J. A. Lopez. 1996. "Forecast Evaluation and Combination." In Handbook of Statistics, Vol. 14, ed. G. S. Maddala and C. R. Rao, 241-68 (chapter 8). Elsevier. 
Elder, R., G. Kapetanios, T. Taylor, and T. Yates. 2005. "Assessing the MPC's Fan Charts." Quarterly Bulletin (Bank of England) (Autumn): 326-48.

Elekdag, S., and P. Kannan. 2009. "Incorporating Market Information into the Construction of the Fan Chart." IMF Working Paper No. 09/178.

European Central Bank. 2007. "Monthly Bulletin" (December).

- 2008. "Monthly Bulletin" (September).

_. 2010. "Monthly Bulletin" (September).

García, J. A., and A. Manzanares. 2007. "What Can Probability Forecasts Tell Us about Inflation Risks?" ECB Working Paper No. 825.

Greene, W. H. 1997. Econometric Analysis. 3rd ed. London: Prentice-Hall International.

Hamilton, J. D. 1989. "A New Approach to the Economic Analysis of Non-stationary Time Series and the Business Cycle." Econometrica 57 (2): 357-84.

International Monetary Fund. 2006. World Economic Outlook. (April).

- 2008. World Economic Outlook. (October).

Kilian, L., and S. Manganelli. 2007. "Quantifying the Risk of Deflation." Journal of Money, Credit and Banking 39 (2-3): 561-90.

Knüppel, M., and G. Schultefrankenfeld. 2011. "Evaluating Macroeconomic Risk Forecasts." Deutsche Bundesbank Discussion Paper Series 1: Economic Studies, No. 14.

Leeper, E. M. 2003. "An 'Inflation Reports' Report.” NBER Working Paper No. 10089.

Machina, M. J., and M. Rothschild. 2008. "Risk." In The New Palgrave Dictionary of Economics, ed. S. N. Durlauf and L. E. Blume. 2nd ed. Palgrave Macmillan.

Magyar Nemzeti Bank. 2004. "Quarterly Report on Inflation" (May). - 2008. "Quarterly Report on Inflation" (May).

Meese, R. A., and K. S. Rogoff. 1983. "Empirical Exchange Rate Models of the Seventies: Do They Fit Out of Sample?" Journal of International Economics 14 (1-2): 3-24.

Mincer, J. A., and V. Zarnowitz. 1969. "The Evaluation of Economic Forecasts." In Economic Forecasts and Expectations: Analysis of Forecasting Behavior and Performance, ed. J. A. Mincer, 1-46 (chapter 1). National Bureau of Economic Research. 
Mitchell, J., and S. G. Hall. 2005. "Evaluating, Comparing and Combining Density Forecasts Using the KLIC with an Application to the Bank of England and NIESR 'Fan' Charts of Inflation." Oxford Bulletin of Economics and Statistics 67 (s1): 995-1033.

Newey, W. K., and K. D. West. 1987. "A Simple, Positive Semi-Definite, Heteroskedasticity and Autocorrelation Consistent Covariance Matrix." Econometrica 55 (3): 703-8.

Norges Bank. 2009. "Monetary Policy Report." No. 1 (March).

Ortega, E., P. Burriel, J. L. Fernández, E. Ferraz, and S. Hurtado. 2007. "Update of the Quarterly Model of the Bank of Spain." Banco de España Working Paper No. 0717.

Pesaran, M. H., and A. Timmerman. 2006. "Testing Dependence Among Serially Correlated Multi-Category Variables." IZA Discussion Paper No. 2196.

Pinheiro, M., and P. S. Esteves. 2010. "On the Uncertainty and Risks of Macroeconomic Forecasts: Combining Judgements with Sample and Model Information." doi: 10.1007/s00181-010-0447-7.

Rasche, R. H., and D. L. Thornton. 2002. "The FOMC's Balanceof-Risks Statement and Market Expectations of Policy Actions." Review (Federal Reserve Bank of St. Louis) 84 (5): 37-50.

Reifschneider, D., and P. Tulip. 2007. "Gauging the Uncertainty of the Economic Outlook from Historical Forecasting Errors." FEDS Paper No. 60, Board of Governors of the Federal Reserve System.

Reserve Bank of Australia. 2008. "Statement on Monetary Policy" (May).

2010. "Statement on Monetary Policy" (August).

Reserve Bank of New Zealand. 2009. "Monetary Policy Statement" (June).

Sveriges Riksbank. 1998. "Inflation Report." No. 2 (June).

. 2005. "Inflation Report." No. 3 (October).

. 2006. "Inflation Report." No. 3 (October).

2007. "Monetary Policy Report" No. 1 (February).

2009. "Monetary Policy Report" (October).

Swiss National Bank. 2008. Quarterly Bulletin 26 (3).

. 2010a. Quarterly Bulletin 28 (1).

2010b. Quarterly Bulletin 28 (2).

2010c. Quarterly Bulletin 28 (3).

Wallis, K. F. 1989. "Macroeconomic Forecasting: A Survey." The Economic Journal 99 (394): 28-61. 
1999. "Asymmetric Density Forecasts of Inflation and the Bank of England's Fan Chart." National Institute Economic Review 167 (1): 106-12.

2003. "Chi-Squared Tests of Interval and Density Forecasts, and the Bank of England's Fan Charts." International Journal of Forecasting 19 (2): 165-75.

2004. "An Assessment of Bank of England and National Institute Inflation Forecast Uncertainties." National Institute Economic Review 189 (1): 64-71.

Wilks, S. S. 1932. "Moments and Distributions of Estimates of Population Parameters from Fragmentary Samples." The Annals of Mathematical Statistics 3 (3): 163-95. 